Prepared for the U.S. Department of Energy

under Contract DE-AC05-76RL01830

\title{
Compliant Glass Seals for SOFC Stacks
}

Yeong-Shyung Chou, Jung-Pyung Choi, Wei Xu, Elizabeth Stephens, Brian Koeppel, and Jeff Stevenson

Pacific Northwest National Laboratory, Richland, WA

Edgar Lara-Curzio

Oak Ridge National Laboratory, Oak Ridge, TN

April 30, 2014

Pacific Northwest

NATIONAL LABORATORY

Proudly Operated by Battelle Since 1965 


\title{
DISCLAIMER
}

This report was prepared as an account of work sponsored by an agency of the United States Government. Neither the United States Government nor any agency thereof, nor Battelle Memorial Institute, nor any of their employees, makes any warranty, express or implied, or assumes any legal liability or responsibility for the accuracy, completeness, or usefulness of any information, apparatus, product, or process disclosed, or represents that its use would not infringe privately owned rights. Reference herein to any specific commercial product, process, or service by trade name, trademark, manufacturer, or otherwise does not necessarily constitute or imply its endorsement, recommendation, or favoring by the United States Government or any agency thereof, or Battelle Memorial Institute. The views and opinions of authors expressed herein do not necessarily state or reflect those of the United States Government or any agency thereof.

\author{
PACIFIC NORTHWEST NATIONAL LABORATORY \\ operated by \\ BATTELLE \\ for the \\ UNITED STATES DEPARTMENT OF ENERGY \\ under Contract DE-AC05-76RL01830
}

Printed in the United States of America
Available to DOE and DOE contractors from the Office of Scientific and Technical Information,
P.O. Box 62, Oak Ridge, TN 37831-0062;
ph: (865) 576-8401
fax: $(865)$ 576-5728
email: reports@adonis.osti.gov

\begin{abstract}
Available to the public from the National Technical Information Service, U.S. Department of Commerce, 5285 Port Royal Rd., Springfield, VA 22161 ph: (800) 553-6847 fax: $(703) 605-6900$ email: orders@ntis.fedworld.gov online ordering: http://www.ntis.gov/ordering.htm
\end{abstract}

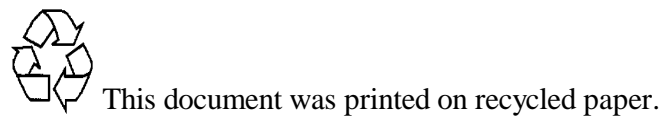




\section{$\underline{\text { Table of Contents }}$}

Executive Summary 2

Introduction 3

Development and Characterization of Self-Healing Glasses

within the SECA Core Technology Program 3

Development of Compliant Glass Seals at ORNL and PNNL 4

Engineered Glass Seals $\quad 5$

$\begin{array}{ll}\text { Fabrication of Seal Materials } & 7\end{array}$

$\begin{array}{lr}\text { Testing of Seal Materials } & 8\end{array}$

$\begin{array}{lr}\text { Compliant Glass Seal Modeling } & 10\end{array}$

$\begin{array}{ll}\text { Conclusions } & 12\end{array}$

$\begin{array}{lr}\text { Acknowledgments } & 13\end{array}$

$\begin{array}{ll}\text { References } & 13\end{array}$

$\begin{array}{ll}\text { Tables } & 15\end{array}$

$\begin{array}{lr}\text { Figures } & 20\end{array}$

Appendix: Modeling of glass seal behavior $\quad 34$ 


\section{Executive Summary}

This report summarizes results from experimental and modeling studies performed by participants in the Solid-State Energy Conversion Alliance (SECA) Core Technology Program, which indicate that compliant glass-based seals offer a number of potential advantages over conventional seals based on de-vitrifying glasses, including reduced stresses during stack operation and thermal cycling, and the ability to heal micro-damage induced during thermal cycling. The properties and composition of glasses developed and/or investigated in these studies are reported, along with results from long-term (up to $5,800 \mathrm{~h}$ ) evaluations of seals based on a compliant glass containing ceramic particles or ceramic fibers. 


\section{Introduction}

The functional requirements of seals for solid oxide fuel cell (SOFC) stacks depend on the specific design and configuration, but in general they include:

- Prevent mixing of fuel and oxidant or mixing of reactants with the ambient environment

- Mechanical bonding of components

- Electrical insulation between stack components

Seal materials must be chemically and physically stable at operating conditions. In some applications (e.g. vehicles), seals must also be able to withstand acceleration forces associated with vibration and shock. Finally, seal materials must be low in cost and amenable to low-cost stack manufacturing methods.

Most SOFC seal research has focused on glasses which, after the sealing process, devitrify into a rigid glass-ceramic mixture. In particular, alkaline earth-based aluminosilicate glasses have been extensively studied due to their appropriate coefficient of thermal expansion (CTE) and sealing temperatures. Recently, an alternative sealing technology based on glasses resistant to de-vitrification has been developed by participants in the SECA Core Technology Program. The primary advantage of this "compliant glass" approach lies in the fact that, in contrast to conventional glass seals that develop a rigid microstructure, a de-vitrification resistant sealing glass with relatively low glass transition temperature $\left(\mathrm{T}_{\mathrm{g}}\right)$ may retain relatively compliant behavior at SOFC operating temperatures, thereby minimizing thermal stress generation during operation. Also, the low $\mathrm{T}_{\mathrm{g}}$ will help to minimize thermal stress generation during stack cooldown, and, if damage (such as micro-crack formation) does occur during cooling to room temperature, there is the potential for self-healing when the SOFC stack is reheated. Finally, compliant glass seals, consisting of crystallization-resistant glass and reinforcing phases, may assist in accommodating stack displacements, thus enabling the assembly and operation of SOFC stacks based on cells having large active surface area, for which dimensional tolerances of flatness and parallelism will be difficult to meet. The purpose of this report is to summarize:

- Properties of candidate compliant glasses and glass/filler composites developed and/or characterized under the SECA Core Technology Program

- Results of long-term testing of compliant glass-based seals under realistic SOFC stack conditions

- Results of modeling of compliant glass seal performance in SOFC stacks

\section{Development and Characterization of Self-Healing Glasses within the SECA Core Technology Program}

A number of organizations including Mo-Sci Corporation, Alfred University, Missouri University of Science \& Technology-Rolla, Sandia National Laboratories, the University of Cincinnati, and Pacific Northwest National Laboratory (PNNL) have developed and characterized glass compositions for SOFC sealing applications as part of the Solid-State Energy Conversion Alliance (SECA) Core Technology Program.

Table I lists the chemical composition and properties of several glasses recently developed at Mo-Sci Corporation (Rolla, MO). Among those glasses, the preferred candidate for a viscous sealing glass for SOFC sealing applications is G102, an alkali-free barium borosilicate 
glass. G102 exhibits stable thermo-mechanical/thermo-chemical properties and excellent thermal stability against crystallization within the SOFC operating temperature range. No bulk crystals were observed in samples of G102 isothermally held at 650,750 , and $850^{\circ} \mathrm{C}$ for up to 2000 hours in air. Even when G102 samples were thermally cycled for 21 days ( 84 cycles) through a temperature range $\left(610-800^{\circ} \mathrm{C}\right)$ that covers the nucleation and growth regions, only surface crystallization was observed. There were no significant changes in the composition or properties (CTE and viscosity) for samples of G102 held for 2000 hours at $800^{\circ} \mathrm{C}$ in air. The long-term (2000 hrs) volatility of G102 was minimal and comparable to that of other sealing glasses at operational temperatures. Al-SS441/G102/YSZ-bilayer sandwich seals remain hermetic after 148 thermal cycles (between room temperature and $800^{\circ} \mathrm{C}$, total process time about 5200 hours) in dry air and wet forming gas. Self-healing of G102 seals cracked by thermal shock was also demonstrated. A seal cracked by thermal shock $\left(>25^{\circ} \mathrm{C} / \mathrm{s}\right)$ was resealed after two hours at temperatures as low as $744^{\circ} \mathrm{C}$ in air, and this seal held pressure to 2 psi when cooled to room temperature.

Table II lists the chemical composition and properties of several glasses recently developed at Alfred University (Alfred, NY). Three preferred glasses were identified; all contained $\mathrm{Ga}_{2} \mathrm{O}_{3}$ up to 15 mole percent to modify the alkaline earth borosilicate base compositions. Testing out to 1000 hours in air, dry $4 \% \mathrm{H}_{2}$ in $\mathrm{N}_{2}$, and wet $100 \% \mathrm{H}_{2}$ showed that all three crystallized extensively but retained some amorphous phase to provide viscous behavior. Testing against alumina-coated stainless steel, YSZ, and spinel coated stainless steel demonstrated excellent compatibility with alumina and YSZ, but not with spinel. ${ }^{1-3}$

\section{Development of Compliant Glass Seals at ORNL and PNNL}

While a broad range of chemical compositions were developed and investigated as part of these SECA-funded projects, in recent work at PNNL and Oak Ridge National Laboratory (ORNL), two commercially available multicomponent silicate glasses containing barium and alkali metals, SCN-1 (SEM-COM, Toledo, OH) and G6 (GE Healthcare Bio Sciences, Pittsburgh, PA), have also been found to exhibit excellent behavior in terms of physical and mechanical properties and long-term stability, including resistance to crystallization. The main constituents and properties of these glasses are listed in Table III.

Studies on these glasses included determination of the chemical composition of the glasses ${ }^{4}$ and characterization of chemical composition evolution as a function of time of exposure to SOFC-relevant environments, such as air and gas mixtures of $\mathrm{H}_{2}+\mathrm{H}_{2} \mathrm{O}+\mathrm{N}_{2}$. The compositions of the SCN-1 and G6 glasses are listed in Table IV. Based on the composition of these glasses, their Young's modulus was calculated using the Makishima-Mackenzie model. ${ }^{5}$ In turn, these values allow for calculation of residual stresses in glass seals at temperatures below the glass transition temperature, when the glass behaves as a solid. Values of Young's modulus for SCN-1 and G6 glasses are plotted in Figure 1 as a function of temperature.

Values for the temperature dependence of the coefficient of thermal expansion, the glass transition temperature and the softening temperature of SCN-1 and G6 glasses were determined using a thermomechanical analyzer, as shown in Figure 2 and described in detail elsewhere 5 . These values are presented in Table III. The viscosity of these glasses was determined using the parallel plate method according to test method ASTM C1351, and is described using the VogelFulcher-Tammann (VFT) model between $550^{\circ} \mathrm{C}$ and $750^{\circ} \mathrm{C}$ (see Table V). 
The microstructural stability of the glass, in particular its resistance to crystallization, is one of the main considerations for the long-term functionality of these glasses in sealing applications. Glasses are in a metastable condition with respect to their crystalline form, so there exists a driving force toward reaching a crystalline state. The time to reach this state will depend on the kinetics of crystallization. Knowledge about these mechanisms is important because glasses containing a significant amount of crystalline phases have shown sluggish healing kinetics even at temperatures much higher than the glass softening temperatures. ${ }^{6}$

The long-term stability of SCN-1 and G6 glasses was investigated in air and in gas mixtures of $\mathrm{H}_{2}+\mathrm{H}_{2} \mathrm{O}+\mathrm{N}_{2}$. These studies, which are described in detailed elsewhere, ${ }^{7}$ were performed by sintering test specimens of these two glasses on alumina or YSZ substrates, followed by monitoring the evolution of the microstructure and the composition of these glasses as a function of time of exposure. Figure 3 shows a collection of micrographs of the crosssectional area of glass beads of SCN-1 and G6 glasses after different periods of time of exposure up to $10,000 \mathrm{hrs}$ at $800^{\circ} \mathrm{C}$. These micrographs show that at the bulk level, the glasses remain amorphous, although evidence of precipitation of crystalline phases within the glass or on the outer surface of the glass beads is observed. From X-ray diffraction measurements and chemical analyses, $\mathrm{KAlSi}_{3} \mathrm{O}_{8}$, barium oxide and a calcium-rich silicate were found to be the main crystalline phases that precipitated from the glass and the volume fraction of $\mathrm{KAlSi}_{3} \mathrm{O}_{8}$ in $\mathrm{SCN}-1$ glass increases with exposure time. While the time dependence of the volume concentration follows the classical Johnson-Mehl-Avrami (JMA) kinetics at exposure times below 5000 hrs, at longer exposure times, deviation from the JMA behavior is observed. This behavior is similar to the crystallization behavior in other glass seal systems. ${ }^{8}$ There are several reasons for deviation from JMA kinetics including the heterogeneous nature of nucleation sites and in the case of SCN-1 glass, the possible exhaustion of potassium and aluminum from the glass matrix at longer exposure times. These micrographs also reveal that the initial distribution of pores in the glass will change with time of exposure. Detailed quantitative analyses of the distribution of pore sizes as a function of time of exposure indicate that small pores will coalesce into larger pores, but that the total porosity remains effectively constant.

\section{Engineered Glass Seals}

One approach for developing megawatt-size SOFC planar systems involves the use of cells with large active area (hundreds of square centimeters). Considering the state of the art for processes to manufacture planar cells, it will be very difficult to fabricate large active area cells with tight tolerances of flatness and parallelism. One potential strategy to enable the use of large surface area cells is to design and use seals with the necessary compliance to accommodate the lack of flatness or parallelism of the cells. ORNL, PNNL, and the National Energy Technology Laboratory (NETL) have developed engineered glass seals that incorporate crystallizationresistant glasses and structural features to accommodate deformation to compensate for the lack of flatness or parallelism.

The engineered glass seals incorporate frangible ceramic particles or ceramic fibers that are chemically and thermoelastically compatible with the crystallization-resistant glass. Among the many options, successful results have been obtained with commercially available hollow zirconia spheres and zirconia fibers (Zircar Ceramics, Florida, NY). The series of schematics in Figure 4 illustrate the principle by which engineered glass seals can seal surfaces that are not parallel or flat. In this case the application of compressive stresses in the direction normal to the 
surfaces to be bonded will fracture the frangible hollow ceramic particles and induce flow of the mixture of glass, ceramic particles and organic binder towards the gaps between the surfaces to be sealed.

One of the positive attributes of engineered glass seals is that their viscosity and mechanical properties can be tailored by varying the concentration of secondary phases in the glass. Figure 5 shows a plot with the temperature dependence of the viscosity of engineered glass seals consisting of SCN-1 glass and different volume concentration of calcia-stabilized zirconia frangible hollow particles. These results show that it is possible to tailor the viscosity of the seal by orders of magnitude over the range of temperatures of interest for the operation of SOFCs by controlling the concentration of secondary ceramic phases (e.g., frangible ceramic particles or ceramic fibers). This is an important attribute that permits sealing a stack with large temperature gradients not just along the length of a stack, but also on the plane of individual cells. This implies that if the temperature distribution in a stack is known in advance, then it is possible to design engineered glass seals with the appropriate value of viscosity depending on the region of the stack where the seal will operate. This would be accomplished by adding a greater concentration of secondary ceramic phases to the crystallization-resistant glass to obtain higher viscosity to seal regions of the cell/stack that are expected to experience higher temperatures than other regions, where a seal with lower viscosity would be used.

Seal materials must be low in cost and amenable to low-cost stack manufacturing methods. Four methods were investigated for the manufacture of engineered glass seals:

- Tape casting

- Screen printing

- Paste extrusion

- Fused deposition

Tape casting is a well-established method in which a slurry is cast onto a moving carrier surface, while a smooth knife edge spreads the slurry to a specified thickness. ${ }^{9}$ In this case the slurry consists of a mixture of an organic binder, glass particles and ceramic particles or ceramic fibers. The resulting tape can be cut into different shapes, as shown in Figure 6, which shows a photograph of a tape of organic binder, hollow calcia-stabilized zirconia particles and SCN-1 glass.

Screen-printing is also a well-established process for manufacturing seals. According to this method a woven mesh over an ink-blocking stencil is used. The stencil forms open areas of mesh that transfer a mixture of a liquid organic binder, glass particles and ceramic particles or fibers, through the mesh as a sharp-edged image onto a substrate. A fill blade or squeegee is moved across the screen stencil, forcing or pumping ink through the mesh openings to wet the substrate during the squeegee stroke. Figure 7 shows a photograph of two patterns of glass (SCN-1 and G6), organic binder and ceramic particles printed onto an YSZ substrate. Each pattern contains two half-moon sections each containing different ratios of ceramic to glass particles (either $3: 1$ or $5: 1$ ). The objective was to demonstrate the feasibility of printing continuous patterns of engineered glass seal containing different concentrations of ceramic particles and therefore, different viscosity. Figure 8 shows the cross-section of the area where the two patterns meet and demonstrates that it is possible to obtain a dense and continuous seal with different concentrations of secondary phases, in this case frangible calcia-stabilized YSZ hollow spheres. This feature, i.e., the ability of having continuous sealing patterns with variable concentration of secondary ceramic particles or fibers, constitutes an advantage of screen 
printing over tape casting. Furthermore, screen printing makes a more effective use of material with minimum waste in contrast to tape casting. A similar method, paste extrusion, uses slurries similar to screen printing slurries. In this process, the sealing paste is applied directly to the sealing regions via extrusion through a nozzle. The process is amenable to automation through the use of computer controlled slurry pumps and X-Y stages.

Fused deposition has been the focus of much interest as part of additive manufacturing processes. The operating principle in fused deposition is the extrusion of a thermoplastic material through a heated nozzle maintained above the glass transition temperature of the thermoplastic. To obtain complex shapes, the nozzle can be moved in three axes according to a preprogrammed pattern as illustrated in Figure 9. The object being fabricated is resting on top of a table and it is being built by moving the nozzle in the $\mathrm{X}-\mathrm{Y}-\mathrm{Z}$ axes. Upon extrusion of the thermoplastic material, it is deposited to build the next layer of the model, where it cools down and solidifies.

Using a mixer extruder, it has been possible to prepare mixtures of glass, ceramic particles and an organic binder, such as PLA (poly-lactic acid), as illustrated in the micrograph in Figure 10, which shows the cross-section of a wire containing 30\% volume fraction of SCN-1 glass particles embedded in a matrix of PLA. When the wire is fed through the heated nozzle at temperatures above the glass transition of the organic binder, this will flow along with the glass and ceramic particles and will be deposited according to a predetermined design. When the deposited material is heated to temperatures above the softening point of the glass, the organic binder will burn out and the glass will melt and sinter, forming a continuous seal. At the time of the preparation of this report wires containing PLA, SCN-1 or G6 glass and ceramic particles or ceramic fibers have been successfully prepared and are being deposited using a 3D printer operating according to the fuse deposition process. The advantage of this approach over tape casting and screen printing is that it is possible to print arbitrary patterns with prescribed concentrations of ceramic particles or ceramic fibers and in turn, specific values of viscosity.

\section{Fabrication of Seal Materials}

\section{Fabrication of glass/zirconia tapes at ORNL}

Polymer tapes loaded with a mixture of glass and zirconia spheres were prepared using conventional non-aqueous tape casting methods.

\section{Fabrication of glass and glass/zirconia pastes at PNNL}

Mixtures of SCN-1 glass powder (sieved through \#100 mesh) and short zirconia fibers (ZYBF-5, Zircar Ceramics, Inc., NY) were ball-milled with iso-propanol for 30 minutes. Pastes were prepared by mixing the glass powder or the glass/fiber mixture with $20-25 \mathrm{wt} \%$ organic binder (ESL450, ElectroScience Laboratories, PA). After homogenization with a 3-roll mill, the paste was de-aired and placed in a syringe for application. 


\section{Testing of Seal Materials}

After promising results were achieved with thermal cycle leak tests performed on small (1" x 1") test coupons, validation tests of plain glass seals and glass/zirconia seals were performed on a larger scale using PNNL's SECA Core Technology Program "single cell stack" test fixture (shown schematically in Figure 11). These single cell tests used commercial Ni-YSZ anode-supported thin YSZ electrolyte cells $(5 \mathrm{~cm}$ x $5 \mathrm{~cm}$ ) with LSM cathodes. AISI 441 interconnect plates (with protective MnCo spinel and alumina coatings in the appropriate areas) were placed on both sides of the cells. Hybrid mica seals were used for the perimeter seal at a compressive load of $\sim 20-30$ psi. Three versions of the compliant seal material were evaluated as cell-to-frame seals. Seals based on plain SCN-1 glass or glass with $15 \%$ zirconia fibers were applied in paste form, while seals based on glass with 17 vol\% crushed zirconia hollow spheres were applied in tape form. A three-step heating profile was used to fabricate the seals: binder burn-out $\left(500^{\circ} \mathrm{C}\right.$ for $\left.2 \mathrm{~h}\right)$, densification $\left(630^{\circ} \mathrm{C}\right.$ for $\left.2 \mathrm{~h}\right)$, and final wetting $\left(850^{\circ} \mathrm{C}\right.$ for $\left.2 \mathrm{~h}\right)$.

The sealed cell-to-frame assemblies were tested for hermeticity (i.e., no evidence of seal penetration by iso-propanol) prior to the assembly of the test stack. ( $\left.\mathrm{La}_{0.8} \mathrm{Sr}_{0.2}\right)_{0.95} \mathrm{MnO}_{3}$ (LSM20) powder (Fuel Cell Materials, OH) and NiO powder (JT Baker, PA) were mixed with organic binders (ESL450, ElectroScience, PA) to form a paste and were applied as cathode and anode contact materials, respectively. Nickel mesh (70x80 of diameter 0.006 ") was spot-welded onto the anode-side of the AISI 441 interconnect. Pt lead wires were used for voltage sensing, and Inconel 600 rods were used as current leads. The stack assembly was heated to $800^{\circ} \mathrm{C}$ in air, followed by anode reduction in $5 \% \mathrm{H}_{2} / \mathrm{N}_{2}$ for $2 \mathrm{~h}$ before switching to the final fuel of $\mathrm{H}_{2}: \mathrm{N}_{2}=1: 1$ with $\sim 3 \% \mathrm{H}_{2} \mathrm{O}$. Air was used as the oxidant.

Two types of cell tests were conducted. The first type - a combined ageing and thermal cycling test - was performed on three versions of the compliant seal: plain SCN-1 glass, glass with 15 vol\% zirconia fibers, and glass with 17 vol\% crushed zirconia hollow spheres. In these tests, the cells were operated in constant current mode at $800^{\circ} \mathrm{C}$ for a total of $1500 \mathrm{~h}$, with an interruption for a deep thermal cycle every $500 \mathrm{~h}$. The second type of cell test was a long-term validation test, which was achieved by continuing the test of the glass with $15 \mathrm{vol} \%$ zirconia fibers beyond $1500 \mathrm{~h}$ until a total test time of $5800 \mathrm{~h}$ was reached. Results of the tests are described below.

\section{Combined Ageing and Thermal Cycling Tests}

Cell voltage versus time for the three different seal tests (plain SCN-1 glass, glass with 15 vol\% zirconia fibers, and glass with 17 vol\% crushed zirconia hollow spheres) is shown in Figure 12. The average degradation rates between thermal cycles were $9.1 \% / \mathrm{kh}, 4.1 \% / \mathrm{kh}$, and $5.2 \% / \mathrm{kh}$ for plain SCN-1 glass. For glass with $15 \%$ zirconia fibers, they were $7.5 \% / \mathrm{kh}, \sim 0 \% / \mathrm{kh}$, and $2.0 \% / \mathrm{kh}$, and for glass with crushed zirconia hollow spheres they were $9.5 \% / \mathrm{kh}, 5.5 \% / \mathrm{kh}$, and $3.6 \% / \mathrm{kh}$. The degradation rate of the test with the best overall performance (glass seal with zirconia fibers) was similar to that of a previous test using a devitrifying glass seal $(\sim 1.1 \% / \mathrm{kh}$ from $t=500$ to $1500 \mathrm{~h}$ ). While all of the tests showed significant degradation in electrochemical performance over time, it is unlikely that the degradation was related to the seals, given that the open circuit voltages remained stable for the duration of the tests, and room temperature testing of the seals, performed by flowing only one gas (fuel or oxidant) to look for cross-over to the other gas bubbler, gave no indication of leakage. After $1500 \mathrm{~h}$, two of the tests (plain SCN-1 glass and glass with crushed zirconia spheres) were terminated and dis-assembled for post-test 
analysis. Liquid penetration tests with iso-propanol indicated hermetic sealing, which is consistent with the high open circuit voltage and lack of gas crossover observed during the test. SEM/EDS analyses of cathode and anode active areas indicated either no presence of alkalis or, at most, a very small amount near the detection limit of $0.5 \%$. As discussed in the next section, the test of the glass seal with zirconia fibers was continued for a longer period of time.

\section{Long-Term Validation Test}

One of the abovementioned aging/thermal cycling tests (the test with a glass/zirconia fiber seal), was selected for continuation as a long-term validation test. The primary motivation for selecting the glass/fiber seal was related to the issue of pore coarsening. Studies at both PNNL and ORNL found that small pores initially present in plain SCN-1 glass coalesced during isothermal aging at elevated temperatures to form very large voids. In an attempt to hinder the pore coarsening processes, inert fillers such as zirconia fibers or crushed zirconia hollow spheres were evaluated. While both forms of inert filler performed well in the 1500 tests described above, supplemental pore coarsening studies indicated that the fibers were the most effective in limiting void growth, so the seal with zirconia fibers was selected for the long-term test.

The results of the test (cell voltage vs. time) are shown in Figure 13. (For comparison, results from a previous test with a devitrifying glass seal are also shown). The first 1500h of the test duplicate the results discussed in the previous section. Note that at $t=1750 \mathrm{~h}$, the cell suffered some damage due to an unscheduled power outage during which the cathode air was shut off and no compressive loading was maintained, in addition to furnace cooling. This disruption led to an abrupt increase in ohmic resistance (as determined by electrochemical impedance spectroscopy) that led to a significant drop in cell voltage. This increase in ohmic resistance was likely due to a loss of contact at the cathode side, so again it is unlikely that the degradation was related to the seals. The open circuit voltage remained stable for the duration of the test, and room temperature testing of the seals, performed by flowing only one gas (fuel or oxidant) to look for cross-over to the other gas bubbler, gave no indication of leakage.

At the conclusion of the test, room temperature leak testing revealed no evidence of gas cross-over. The cell assembly was then dis-assembled for post-test analysis. Liquid penetration tests with iso-propanol indicated hermetic sealing, and examination with optical microscopy found no evidence of seal damage or failure. The anode appeared to be completely reduced, without any discoloration or greenish color indicative of Ni oxidation. One potential concern when using non-crystallizing glasses for SOFC sealing applications is the possibility of squeezing the glass out of the bonding area because of compressive loading either externally applied or resulting from the weight of the stack. No spreading of the glass was observed after the long-term test, but if this issue arises in larger scale cells and stacks, it could be addressed by using spacers (e.g., mica paper) to maintain the desired seal thickness.

Cross-section SEM/EDS was used to characterize the microstructure and chemistry of the anode and cathode. Except for a small amount of $\mathrm{Na}(<1$ at $\%)$ that was detected in the cathode current collection layer, levels of $\mathrm{Na}, \mathrm{K}$, and $\mathrm{Si}$ were at or below the detection limit. Glass interactions with the two mating materials were also examined along the glass/YSZ electrolyte and glass/aluminized AISI441 cell frame interfaces. Two typical microstructure images of the glass/YSZ electrolyte interface are shown in Figure 14. Five areas were selected for EDS chemical analysis; the results are listed in Table VI. The interaction between the glass and YSZ electrolyte was minimal, as evidenced by the absence of $\mathrm{Zr}$ in the glass. This is consistent with 
the smooth YSZ/glass interface and the homogeneous appearance of the YSZ electrolyte, which indicates no leaching or corrosion along the YSZ grain boundaries.

Two typical microstructure images along the glass/aluminized AISI441 interconnect are shown in Figure 15; results of EDS spot analysis are listed in Table VII. Overall, the alumina protection layer was intact, with no evidence of de-bonding from the metal substrate. Only minute concentrations of metal species were detected in the glass matrix. In addition, no significant precipitation was found in the glass along the glass/alumina interface, indicating good chemical compatibility with the alumina protection layer. Figure 16A shows a lower magnification image of a typical portion of the engineered glass seal after the long-term stability test. Note that the majority of the pores are somewhat irregular in shape, indicating the effectiveness of the zirconia fibers in hindering the coalescence of pores. For comparison, an SEM image of plain SCN-1 glass (no fillers) sealed between two bilayers and aged for only $500 \mathrm{~h}$ at $800^{\circ} \mathrm{C}$ shows the presence of large spherical pores that in some cases span the width of the seal (Figure 16B). This indicates the potential benefit of including inert fillers in the compliant glass SCN-1 when designing seals for SOFC stacks.

\section{Compliant Glass Seal Modeling}

The thermo-mechanical performance of compliant glass seals in SOFC stacks under various operating conditions was systematically investigated through numerical models. A fully three-dimensional thermo-visco-elastic-damage-healing constitutive model was developed to capture the unique stress-strain material behavior of the glass. The evolution kinetics of the two major damage sources, i.e. CTE mismatch-induced mechanical cracks and changes in seal porosity, are described in detail in Appendix A and Reference. ${ }^{10}$ The proposed material model was calibrated with experimentally obtained properties and then implemented in finite element (FE) analyses through user-subroutines in the commercial FE code ABAQUS. The mechanical performance of single- and multi-cell SOFC stacks was then examined. The major findings from this study are summarized below and in Appendix A.

Two types of SOFCs were modelled. One corresponded to PNNL's SECA Core Technology Program stack test fixture, while the other corresponded to a larger 10x10 cm planar design that more closely resembled full-sized SECA cells and stacks. In both cases, glass seals joined the electrolyte layer to the metallic cell frame. Multi-cell stack models were generated by sequentially repeating the single-cell units.

A typical damage accumulation and dissipation response of the seal glass during a single thermal cycle (cooling from the fabrication temperature to room temperature, followed by reheating to the operating temperature) is shown in Figure 17, with the volume-averaged damage due to cracks and pores separately exhibited. In this study, "damage" is defined as the fractional reduction in elastic modulus. Overall, the damage generated within the sealant was found to be trivial and unlikely to result in noticeable performance reduction, which is consistent with experimental observations with the SECA stack test fixture. Furthermore, the relatively low viscosity of the glass at operating temperature would likely lead to healing of any minor damage caused by thermal cycling. Overall, as might be expected, the rate of temperature change and loading conditions dominated damage behavior, with less damage occurring with lower stresses and more gradual temperature changes.

The seal reliability of a three-cell SOFC stack (PNNL stack fixture) during multiple thermal cycles was also evaluated. Similar to previous experimental measurements, ${ }^{11}$ the 
mechanical integrity of the glass seal was predicted to be minimally impacted by 10 deep thermal cycles, as shown in Figure 18. Although pore-related damage was initially lower in magnitude than cracking damage, its continuous increase with increasing number of cycles could eventually lead to a loss of seal integrity. Furthermore, the continuous increase in pore-related damage (primarily represented by increased pore size due to pore coalescence), may enhance crack initiation, as evidenced by the increasing height of the crack damage peaks. However, predicted results also indicate that the pore damage rate tends to saturate over time which would suggest a more optimistic projection on the long-term performance of the seal. Further experimental and modeling analyses focused on long-term operations and performance are expected to strengthen such confidence.

Since the electrochemical reactions that occur during SOFC operation can strongly affect the temperature fields within SOFC stacks, the effects of associated operating parameters were also investigated by integrating the FE analysis with the SOFC-MP multi-physics computational capabilities. ${ }^{12,13}$ Operational variables such as thermal boundary conditions, current density, fuel utilization, and fuel composition were considered. Figure 19 shows results for a single thermal cycle of a single cell repeat unit representative of a commercial-scale SOFC stack.

As shown in the figure, although the repeat unit behaved quite similarly under adiabatic, furnace, and insulated self-heating conditions, the non-adiabatic case showed slightly less porerelated damage and slower healing because of the lower internal temperatures (3a). Although increases in fuel utilization and power density tend to yield larger temperature gradients which can introduce more stress concentrations and damage, seal damage for both a low power/fuel utilization and high power/fuel utilization case were similar (3b). The difference between methane-powered and hydrogen-powered SOFCs also appeared to be trivial, although the comparatively more uniform temperature field for methane produced slightly less mechanical degradation (3c).

The predicted seal performance of a larger three-cell SOFC stack during multiple thermal cycles is shown in Figure 20. It is apparent that the mechanical degradation within the seal is quite low even after 10 deep thermal cycles, following a trend similar to that of the PNNL stack fixture.

The viscosity and the elastic modulus are both important design metrics for compliant glass. For example, higher values of elastic modulus can promote damage due to the intensified stress field. Glass viscosity influences the damage response in a mechanism-dependent manner. Figures 21(a)-(b) show the predicted variation of damage with viscosity for cases where different damage sources dominate. It was found that, when cracking is dominant, higher viscosity results in more damage because of the hindered stress relaxation. On the other hand, when pore evolution is dominant, increasing viscosity will reduce damage by preventing flow-driven pore coarsening until a limiting viscosity corresponding to the increase in the stress concentration effect is met. These findings could potentially reconcile the contradictory experimental observations reported in the open literature ${ }^{14,15}$ and can also provide guidance to material customization, i.e. addition of a reinforcement phase to mitigate pore coarsening.

A comparison between mechanical responses of the compliant $\mathrm{SCN}-1$ glass and a stateof-the-art devitrifying glass (PNNL's G18), shown in Figure 22, illustrates the benefits that compliant glass seals can bring to SOFC technology. It is clear that the compliant glass accumulates much less damage than the devitrifying glass under the same thermo-mechanical operations. The compliant nature of the $\mathrm{SCN}-1$ glass is believed to be the underlying root cause, 
as stress concentrations can be quickly relaxed. Moreover, with its healing capability upon reheating, most of the lost structural integrity can be effectively recovered.

The main findings from the modeling study can be summarized as follows:

1) The present $3 \mathrm{D}$ thermo-visco-elastic coupled continuum damage-healing glass model is able to capture the essential nonlinear material behaviors of SOFC glass sealant under short-term stack operating conditions including the underlying mechanisms accounting for different mechanical degradation and recovery physics. The overall damage within the compliant seal was found to be trivial even under aggressive operating conditions.

2) It has also been found that cracking damage occurring during thermal cycling can be completely repaired at high temperature due to the prevailing inter-diffusion while pore coarsening-induced material degradation tends to accumulate over the time/operational cycles. The addition of reinforcement phases to prevent the viscous flow is a conceptually viable solution to reduce pore growth, although its effectiveness and applicability should be quantitatively characterized through further high-fidelity modeling.

3) Thermo-electro-chemical conditions such as thermal boundary conditions, power density, and fuel composition are important operating parameters, and internal cracking damage can be further eliminated through more gradual environmental temperature changes.

4) Compared to a rigid devitrifiying glass-ceramic such as G18, the $\mathrm{SCN}-1$ compliant glass is found to have clear advantages in terms of the ability to minimize and mitigate damage by effectively relaxing the stress concentrations.

\section{Conclusions}

Experimental and modeling studies performed by participants in the Solid-State Energy Conversion Alliance (SECA) Core Technology Program indicate that compliant glass-based seals offer a number of potential advantages over conventional seals based on de-vitrifying glasses, including reduced stresses during stack operation and thermal cycling, and the ability to heal micro-damage induced during thermal cycling. Subsequent to the development of a comprehensive understanding of the thermo-physical and mechanical properties of a variety of candidate sealing glasses, seals based on one of the candidate glasses (SCN-1, with and without modifying fillers) were fabricated and tested under stack-like conditions. The seal tests, which included a long-term $(5800 \mathrm{~h})$ validation test, demonstrated the viability of the compliant glass seal approach for SOFC stack sealing applications. This viability was further demonstrated through modeling of multi-cell SOFC stacks, which indicated minimal damage within the seals during thermal cycling and self-healing capability upon returning the seals to operating temperature. While most of the validation testing was focused on one specific glass (SCN-1), other glasses developed and/or characterized by participants in the SECA Core Technology Program would also merit consideration when designing a compliant glass seal for a specific stack design and set of operating conditions. 


\section{Acknowledgments}

The work summarized in this report was funded by the DOE Office of Fossil Energy's Solid-state Energy Conversion Alliance (SECA). The authors appreciate helpful discussions with the NETL SECA Program management team, and thank Scott Misture (Alfred University) and C.W. Kim (Mo-Sci Corporation) for providing information regarding their compliant glass development. The following contributors at ORNL are also acknowledged: Beth Armstrong, Valerie Garcia-Negron, John Henry, Melanie Kirkham, Andres Marquez, Dana McClurg, Roberta A. Meisner, Amit Shyam, Hannah Stokes, Rosa Trejo, Yanli Wang, and Shirley Waters.

\section{References}

1. M.O. Naylor, T. Jin, J.E. Shelby, and S.T. Misture, "Galliosilicate Glasses for Viscous Sealants in Solid Oxide Fuel Cell Stacks, Part I: Compositional Design,” Int. J. Hydrogen Energy, 38, 16300-16307 (2013).

2. S.T. Misture, M.O. Naylor, T. Jin, and J.E. Shelby, "Galliosilicate Glasses for Viscous Sealants in Solid Oxide Fuel Cell Stacks, Part II: Interactions with Yttria Stabilized Zirconia and Stainless Steel Coated with Alumina," Int. J. Hydrogen Energy, 38, 1632816337 (2013).

3. T. Jin, M.O. Naylor, J.E. Shelby, and S.T. Misture, "Galliosilicate Glasses for Viscous Sealants in Solid Oxide Fuel Cell Stacks, Part III: Behavior in Air and Humidified Hydrogen,” Int. J. Hydrogen Energy, 38, 16308-16319 (2013).

4. J. M. Giaquinto, C. K. Bayne, D. C. Glasgow, R. H. Ilgner, and T. J. Keever, "Uncertainty Study for the Measurement of Elemental Composition in Glass Specimens," Oak Ridge National Laboratory Internal Report (2010).

5. R. Trejo, E. Lara-Curzio, A. Shyam, M. J. Kirkham, V. Garcia-Negron, and Y. Wang, "Physical and Mechanical Properties of Barium Alkali Silicate Glasses for SOFC Sealing Applications," International Journal of Applied Glass Science, 3, 369-379 (2012).

6. R. N. Singh, "Sealing Technology for Solid Oxide Fuel Cells (SOFC)," Int. J. Appl. Ceram. Technol., 4 [2] 134-144 (2007).

7. A. Shyam, R. Trejo, D. McClurg, A. Ladouceur, M. Kirkham, X.Y. Song, J. Howe, and E. Lara-Curzio, "Microstructural evolution in two alkali multicomponent silicate glasses as a result of long-term exposure to solid oxide fuel cell environments," Journal of Materials Science, Volume: 48, Issue: 17, pp: 5880-5898 (2013). 
8. M.K. Mahapatra and K. Lu, "Glass-based seals for solid oxide fuel and electrolyzer cells A review," Materials Science and Engineering, R 67 (2010) 65-85.

9. W. D. Kingery, H. K. Bowden and D. R. Uhlmann, Introduction to Ceramics, 2nd. Edition, John Wiley, 1976.

10. W. Xu, X. Sun, B.J. Koeppel, H. Zbib, International Journal of Plasticity, submitted, (2014).

11. Y. Chou, E.C. Thomsen, J.P. Choi, J.W. Stevenson, Journal of Power Sources, 197 (2012) 154160.

12. B.J. Koeppel, K. Lai, M.A. Khaleel, SOFC-MP 2D User Manual, 2011.

13. K. Lai, B.J. Koeppel, K.S. Choi, K.P. Recknagle, X. Sun, L.A. Chick, V. Korolev, M.A. Khaleel, Journal of Power Sources, 196 (2011) 3204-3222.

14. Y.I. Kim, D.H. Lee, W.J. Kim, S. Park, H.N. Kim, D.B. Lee, J.C. Lee, Reviews on Advanced Materials Science, 28 (2011) 111-115.

15. D.B. Lee, M.J. Choi, S. Park, J.C. Lee, Journal of Nanoscience and Nanotechnology, 13 (2013) 628-631. 


\section{Tables}

Table I. Chemical composition and properties of silicate glasses developed by Mo-Sci Corporation as part of the SECA Core Technology Program. Primary constituents are designated in blue.

\begin{tabular}{|c|c|c|c|c|c|c|c|c|c|c|c|c|c|c|c|c|}
\hline & \multicolumn{13}{|c|}{ Elements } & & & \\
\hline Glass ID & B & $\mathrm{Na}$ & $\mathrm{Mg}$ & $\mathrm{Al}$ & $\mathrm{K}$ & $\mathrm{Ca}$ & $\mathrm{Zn}$ & $\mathrm{Ga}$ & $\mathrm{Ge}$ & $\mathrm{Sr}$ & $\mathrm{Y}$ & $\mathrm{Zr}$ & $\mathrm{Ba}$ & $\mathrm{Tg}$ & Ts & cte \\
\hline G2 & & & & & & & & & & & & & & 619 & 650 & 8.19 \\
\hline G4 & & & & & & & & & & & & & & 599 & 632 & 7.32 \\
\hline G28 & & & & & & & & & & & & & & 581 & 615 & 7.48 \\
\hline G73 & & & & & & & & & & & & & & 624 & 640 & 8.48 \\
\hline G74 & & & & & & & & & & & & & & 591 & 616 & 8.19 \\
\hline G75 & & & & & & & & & & & & & & 623 & 650 & 8.17 \\
\hline G76 & & & & & & & & & & & & & & 573 & 604 & 7.06 \\
\hline G77 & & & & & & & & & & & & & & 625 & 656 & 9.25 \\
\hline G102 & & & & & & & & & & & & & & 604 & 639 & 7.25 \\
\hline
\end{tabular}


Table II. Chemical composition and properties of silicate glasses developed by Alfred University as part of the SECA Core Technology Program. Primary constituents are designated in blue.

\begin{tabular}{|c|c|c|c|c|c|c|c|c|c|c|c|c|c|c|}
\hline & \multicolumn{12}{|c|}{ Element } & & \\
\hline Glass ID & B & $\mathrm{Na}$ & $\mathrm{Al}$ & $\mathrm{K}$ & $\mathrm{Ca}$ & $\mathrm{Zn}$ & $\mathrm{Ga}$ & $\mathrm{Ge}$ & $\mathrm{Sr}$ & $\mathrm{Y}$ & $\mathrm{Zr}$ & $\mathrm{Ba}$ & $\begin{array}{l}\mathrm{Tg} \\
\left({ }^{\circ} \mathrm{C}\right)\end{array}$ & $\begin{array}{c}\text { cte } \\
\left(\mathrm{ppm} \mathrm{K}^{-1}\right)\end{array}$ \\
\hline GaSi1 & & & & & & & & & & & & & 647 & 9.2 \\
\hline GaSi2 & & & & & & & & & & & & & 640 & 10.1 \\
\hline GaSi3 & & & & & & & & & & & & & 670 & 8.1 \\
\hline & & & & & & & & & & & & & & \\
\hline BGS1 & & & & & & & & & & & & & 544 & 7.9 \\
\hline BGS2 & & & & & & & & & & & & & 590 & 10.1 \\
\hline BGS3 & & & & & & & & & & & & & 574 & 9.1 \\
\hline BGS4 & & & & & & & & & & & & & 555 & 9 \\
\hline BGS5 & & & & & & & & & & & & & 669 & 7.7 \\
\hline BGS6 & & & & & & & & & & & & & & \\
\hline HTSi1 & & & & & & & & & & & & & 504 & 110 \\
\hline & & & & & & & & & & & & & & \\
\hline HTS12 & & & & & & & & & & & & & 640 & 11.8 \\
\hline HTSi3 & & & & & & & & & & & & & & \\
\hline HTSi4 & & & & & & & & & & & & & 750 & 8.9 \\
\hline HTSi5 & & & & & & & & & & & & & 770 & 9.7 \\
\hline HTSi6 & & & & & & & & & & & & & 725 & 10.5 \\
\hline HTSi7 & & & & & & & & & & & & & 760 & 10.2 \\
\hline HTSi8 & & & & & & & & & & & & & 671 & 10 \\
\hline HTSi9 & & & & & & & & & & & & & 679 & 10.5 \\
\hline HTSi10 & & & & & & & & & & & & & & \\
\hline HTSi11 & & & & & & & & & & & & & & \\
\hline
\end{tabular}

Table III. Chemical composition and properties of commercial glasses SCN (SEM-COM, Inc., Toledo, OH) and G6 (GE Healthcare Bio-Sciences,Pittsburgh, PA). Primary constituents are designated in blue.

\begin{tabular}{|l|l|l|l|l|l|l|l|l|l|l|l|l|l|l|l|}
\hline & & & & & & & & & & & & & & \\
\hline Glass ID & B & Na & Mg & Al & K & Ca & Ti & Fe & Zn & Sr & Ba & & $\begin{array}{l}\text { Tg } \\
\left({ }^{\circ} \mathrm{C}\right)\end{array}$ & $\begin{array}{c}\text { Ts } \\
\left({ }^{\circ} \mathrm{C}\right)\end{array}$ & $\begin{array}{c}\text { Thermal } \\
\text { expansion } \\
\left(\mathrm{K}^{-1}\right)\end{array}$ \\
\hline SCN & & & & & & & & & & & & & 468 & 550 & $\begin{array}{c}9.97 \times 10^{-6}+ \\
\left(7.79 \times 10^{-9}\right) \mathrm{T}\end{array}$ \\
\hline G6 & & & & & & & & & & & & & 508 & 600 & $\begin{array}{c}7.25 \times 10^{-6}+ \\
\left(6.67 \times 10^{-9}\right) \mathrm{T}\end{array}$ \\
\hline
\end{tabular}


Table IV. Chemical composition of SCN and G6 glasses. Values were determined by inductively coupled plasma mass spectrometry (ICPMS) and inductively coupled plasma-Atomic Emission Spectrometry (ICPAES).

\begin{tabular}{lcc}
\hline & \multicolumn{2}{c}{ Weight\% } \\
\cline { 2 - 3 } Element & ICP-MS & ICP-AES \\
\hline SCN-1 & \\
$\mathrm{Si}$ & 51.9 & 54.8 \\
$\mathrm{~K}$ & 15.0 & 13.4 \\
$\mathrm{Ba}$ & 14.0 & 12.9 \\
$\mathrm{Na}$ & 9.8 & 8.3 \\
$\mathrm{Ca}$ & 3.9 & 5.0 \\
$\mathrm{Al}$ & 3.4 & 3.4 \\
$\mathrm{Mg}$ & 1.2 & 1.3 \\
$\mathrm{Ti}$ & 0.5 & 0.6 \\
$\mathrm{~B}$ & 0.1 & 0.1 \\
$\mathrm{Zn}$ & 0.1 & 0.0 \\
$\mathrm{G6}$ & & \\
$\mathrm{Si}$ & 50.5 & 53.4 \\
$\mathrm{Na}$ & 15.5 & 12.6 \\
$\mathrm{Ba}$ & 7.7 & 7.2 \\
$\mathrm{~B}$ & 6.3 & 6.0 \\
$\mathrm{Zn}$ & 5.8 & 5.8 \\
$\mathrm{Al}$ & 5.2 & 5.1 \\
$\mathrm{Ca}$ & 4.1 & 5.0 \\
$\mathrm{~K}$ & 3.2 & 3.2 \\
$\mathrm{Mg}$ & 1.5 & 1.6 \\
$\mathrm{Fe}$ & 0.2 & 0.1 \\
\hline
\end{tabular}


Table V. Temperature dependence of viscosity of selected glasses.

a) Temperature dependence of viscosity of Mo-Sci glasses between $600^{\circ} \mathrm{C}$ and $800^{\circ} \mathrm{C}$.

\begin{tabular}{|c|c|c|c|}
\hline \multirow{2}{*}{ Glass } & \multicolumn{3}{|c|}{ Corning Viscosity Model Fitting Parameters } \\
\cline { 2 - 4 } & $\mathrm{m}$ & $\operatorname{Tg}\left({ }^{\circ} \mathrm{C}\right)$ & $\log \eta_{\infty}$ \\
\hline $\mathrm{G} 73$ & 64.13 & 606 & -3.5 \\
\hline $\mathrm{G} 102$ & 57.18 & 593 & -3.3 \\
\hline
\end{tabular}

$\log \eta(T)=\log \eta_{\infty}+\left(12-\log \eta_{\infty}\right) \frac{T_{g}}{T} \exp \left[\left(\frac{m}{12-\log \eta_{\infty}}-1\right)\left(\frac{T_{g}}{T}-1\right)\right]$

b) Temperature dependence of viscosity of SCN glass (Vogel-Fulcher-Tammann (VFT) model) between $550^{\circ} \mathrm{C}$ and $750^{\circ} \mathrm{C}$. Temperature in ${ }^{\circ} \mathrm{C}$.

$\log \eta(T)=-6.007+\frac{9129.7}{T+33.46}$

c) Temperature dependence of viscosity of G6 glass (Vogel-Fulcher-Tammann (VFT) model) between $550^{\circ} \mathrm{C}$ and $750^{\circ} \mathrm{C}$. Temperature in ${ }^{\circ} \mathrm{C}$.

$\log \eta(T)=-3.126+\frac{3917.5}{T-295.45}$ 
Table VI. Chemical analyses of selected areas shown in Figure 14A and 14B.

from figure $14 \mathrm{~A}$

\begin{tabular}{|c|c|r|r|r|r|r|r|r|r|}
\hline Area & \multicolumn{1}{c|}{$\mathrm{O}$} & \multicolumn{1}{c|}{$\mathrm{Mg}$} & \multicolumn{1}{c|}{$\mathrm{Al}$} & \multicolumn{1}{c|}{$\mathrm{Si}$} & \multicolumn{1}{c|}{$\mathrm{K}$} & \multicolumn{1}{c|}{$\mathrm{Ca}$} & \multicolumn{1}{c|}{$\mathrm{Ni}$} & \multicolumn{1}{c|}{$\mathrm{Zr}$} & \multicolumn{1}{c|}{$\mathrm{Ba}$} \\
\hline$\# 1$ & 71.33 & & & & & & 0.80 & 27.87 & \\
\hline$\# 2$ & 66.35 & 0.53 & 1.67 & 27.82 & 1.59 & 0.37 & 0.11 & 0.85 & 0.71 \\
\hline$\# 3$ & 65.32 & 0.69 & 1.82 & 29.24 & 1.56 & 0.40 & 0.09 & & 0.88 \\
\hline$\# 4$ & 65.71 & 0.72 & 1.71 & 27.97 & 1.48 & 1.41 & 0.07 & & 0.94 \\
\hline$\# 5$ & 65.29 & 0.68 & 1.73 & 28.07 & 1.53 & 1.73 & 0.06 & & 0.90 \\
\hline
\end{tabular}

from figure 14B

\begin{tabular}{|c|c|r|r|r|r|r|r|r|r|}
\hline Area & \multicolumn{1}{c|}{$\mathrm{O}$} & \multicolumn{1}{c|}{$\mathrm{Mg}$} & \multicolumn{1}{c|}{$\mathrm{Al}$} & \multicolumn{1}{c|}{$\mathrm{Si}$} & \multicolumn{1}{c|}{$\mathrm{K}$} & $\mathrm{Ca}$ & $\mathrm{Ni}$ & $\mathrm{Zr}$ & $\mathrm{Ba}$ \\
\hline$\# 1$ & 71.01 & & & & & & 1.25 & 27.74 & \\
\hline$\# 2$ & 66.18 & 0.51 & 1.81 & 29.52 & 1.39 & & 0.10 & & 0.36 \\
\hline$\# 3$ & 65.75 & 0.72 & 1.78 & 28.88 & 1.17 & 0.90 & 0.08 & & 0.58 \\
\hline$\# 4$ & 65.66 & 0.77 & 1.77 & 28.21 & 1.13 & 1.52 & 0.06 & & 0.70 \\
\hline$\# 5$ & 65.74 & 0.81 & 1.74 & 28.12 & 1.06 & 1.70 & & & 0.83 \\
\hline
\end{tabular}

Table VII. Chemical analyses of selected spots shown in Figure 15A and 15B.

from figure $15 \mathrm{~A}$
\begin{tabular}{|c|r|r|r|r|r|r|r|r|r|r|r|r|r|}
\hline Spot & \multicolumn{1}{c|}{$\mathrm{O}$} & $\mathrm{Mg}$ & \multicolumn{1}{c|}{$\mathrm{Al}$} & \multicolumn{1}{c|}{$\mathrm{Si}$} & $\mathrm{K}$ & $\mathrm{Ca}$ & $\mathrm{Ti}$ & $\mathrm{Cr}$ & $\mathrm{Fe}$ & $\mathrm{Zr}$ & $\mathrm{Ag}$ & $\mathrm{Ba}$ \\
\hline$\# 1$ & 61.84 & & 36.19 & 0.35 & & & 0.08 & 0.26 & 0.84 & & 0.43 & \\
\hline$\# 2$ & 60.69 & & 36.90 & 1.21 & & 0.28 & & 0.08 & 0.19 & & 0.40 & 0.23 \\
\hline$\# 3$ & 65.17 & 0.77 & 1.92 & 29.07 & 2.04 & 0.22 & 0.22 & & 0.06 & & & 0.53 \\
\hline$\# 4$ & 62.43 & & 0.27 & 20.94 & 0.38 & 10.64 & & & & & & 5.33 \\
\hline$\# 5$ & 70.19 & & & & & & & & 0.25 & 29.56 & & \\
\hline
\end{tabular}

from figure 15B
\begin{tabular}{|c|r|r|r|r|r|r|r|r|r|r|r|r|r|}
\hline Spot & \multicolumn{1}{c|}{$\mathrm{O}$} & $\mathrm{Mg}$ & \multicolumn{1}{c|}{$\mathrm{Al}$} & \multicolumn{1}{c|}{$\mathrm{Si}$} & $\mathrm{K}$ & $\mathrm{Ca}$ & $\mathrm{Ti}$ & $\mathrm{Cr}$ & $\mathrm{Mn}$ & $\mathrm{Fe}$ & $\mathrm{Zr}$ & $\mathrm{Ag}$ & $\mathrm{Ba}$ \\
\hline$\# 1$ & 61.89 & & 36.96 & 0.24 & & & 0.12 & 0.10 & & 0.23 & & 0.46 & \\
\hline$\# 2$ & 63.20 & 0.46 & 25.21 & 8.01 & & 0.51 & 0.85 & 0.14 & 1.17 & 0.14 & & 0.21 & \\
\hline$\# 3$ & 64.11 & 1.02 & 1.79 & 29.28 & 1.42 & 1.20 & & & & & & & 1.18 \\
\hline$\# 4$ & 61.71 & & & 20.30 & 0.13 & 12.02 & & & & & & & 5.84 \\
\hline$\# 5$ & 69.80 & & & & & & & & & & 29.91 & & \\
\hline$\# 6$ & 64.71 & 1.30 & 1.90 & 28.18 & 1.42 & 0.72 & & & & & & & 1.76 \\
\hline
\end{tabular}




\section{Figures}

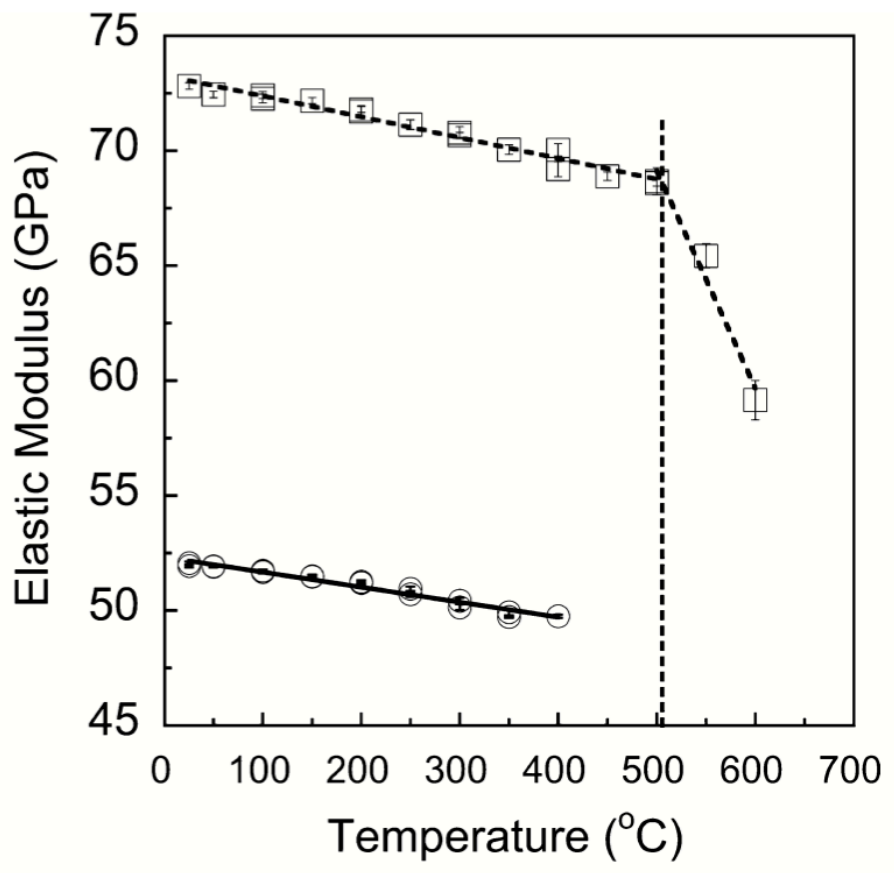

Figure 1. Young's modulus of SCN (circles) and G6 (squares) glasses as a function of temperature using resonant ultrasound spectroscopy. The onset of the rapid decrease of Young's modulus coincides with the value of the glass transition temperature determined from thermal expansion measurements.

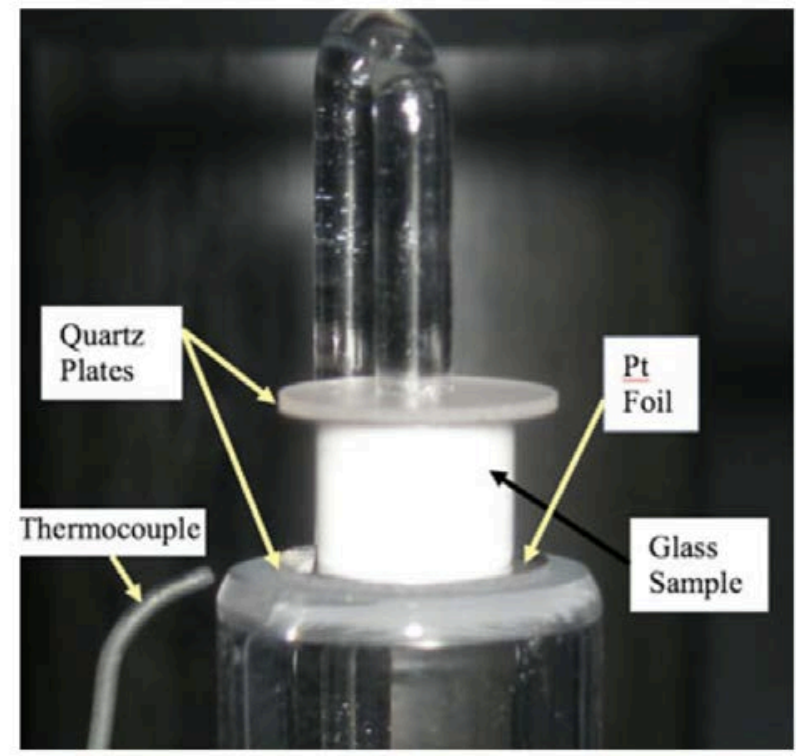

Figure 2. Photograph of thermomechanical analyzer used to determine the thermal expansion and the glass transition and softening temperatures of glasses. 


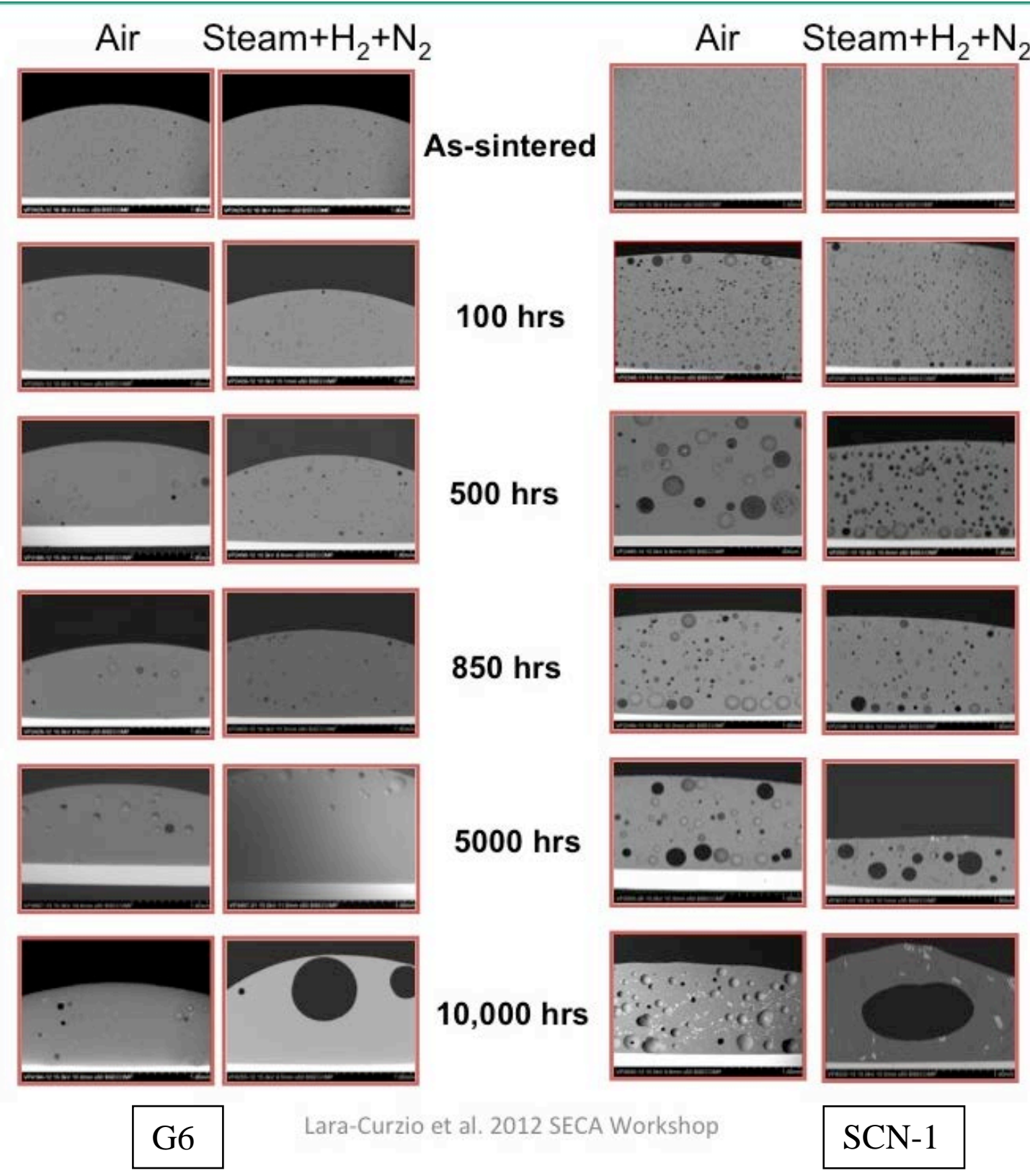

Figure 3. Micrographs of the cross-section of both SCN and G6 glass beads sintered onto YSZ substrates at $800 \mathrm{C}$ as a function of time of exposure in air or gas mixtures of $\mathrm{H}_{2}+\mathrm{H}_{2} \mathrm{O}+\mathrm{N}_{2}$. 
(a)
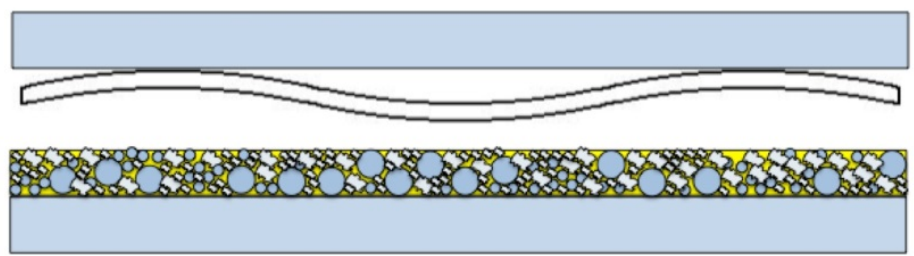

(b)

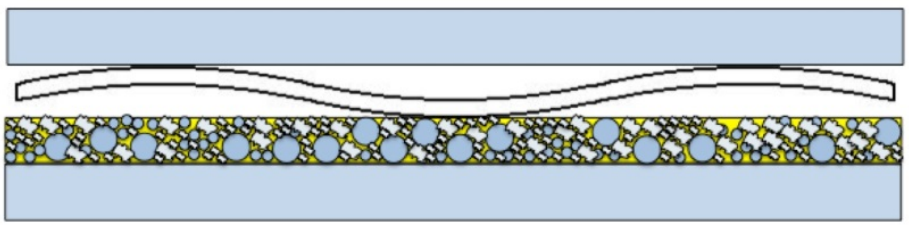

(c)

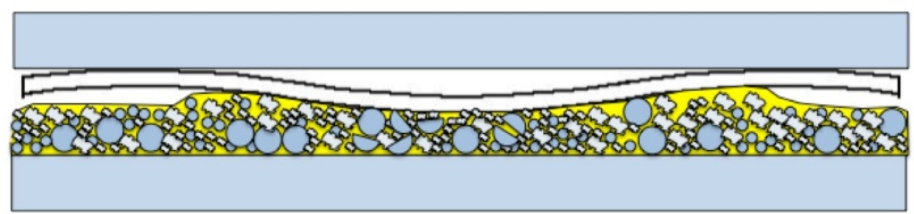

(d)

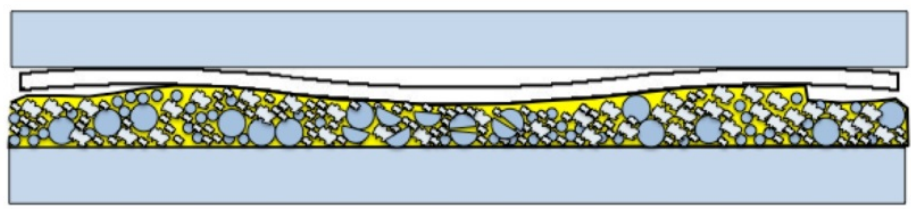

(e)

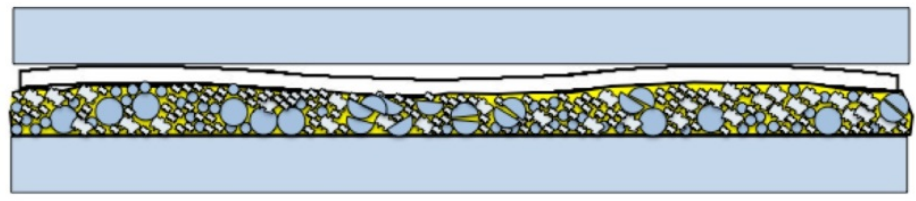

(f)

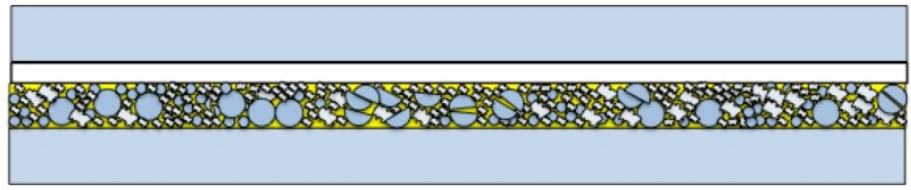

Figure 4. Schematic illustrations of the principle by which engineered glass seals can seal surfaces that are not parallel or flat. 


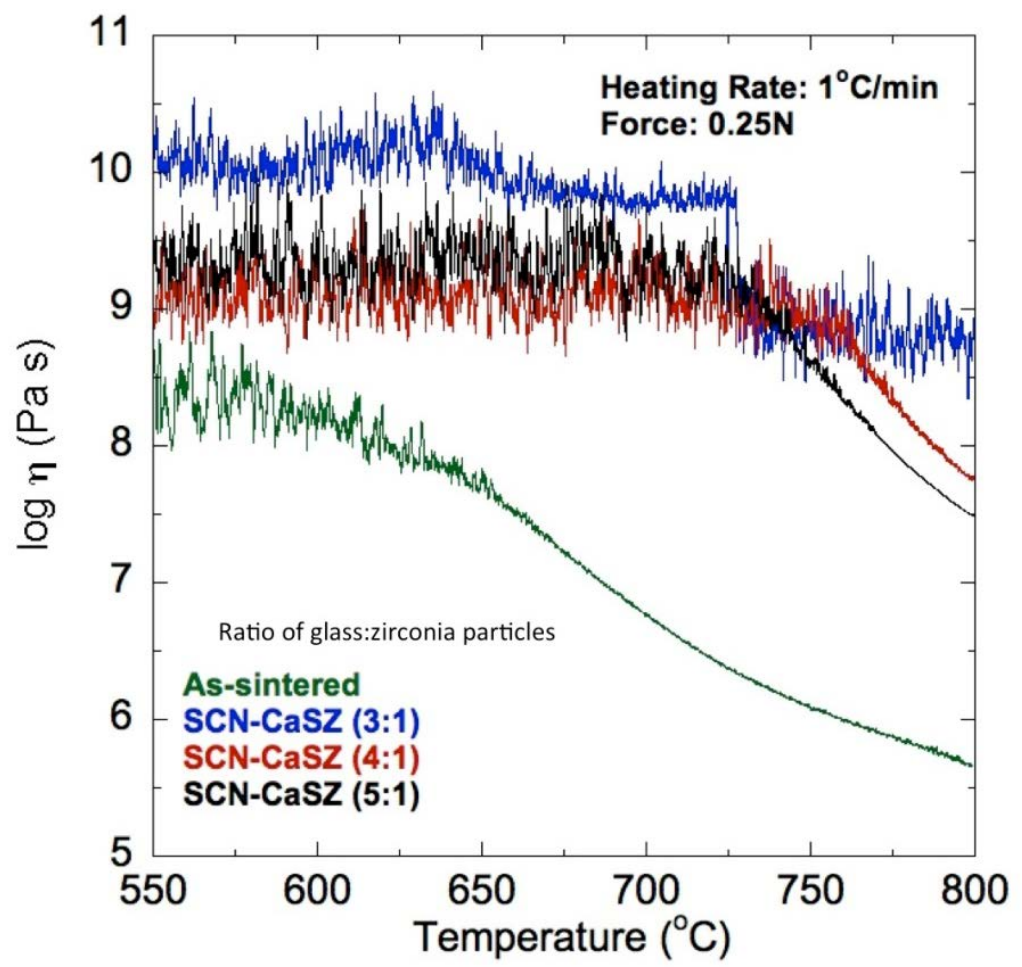

Figure 5. Temperature dependence of the viscosity of engineered glass seals consisting of SCN glass and different volume concentrations of calcia-stabilized zirconia frangible hollow particles.

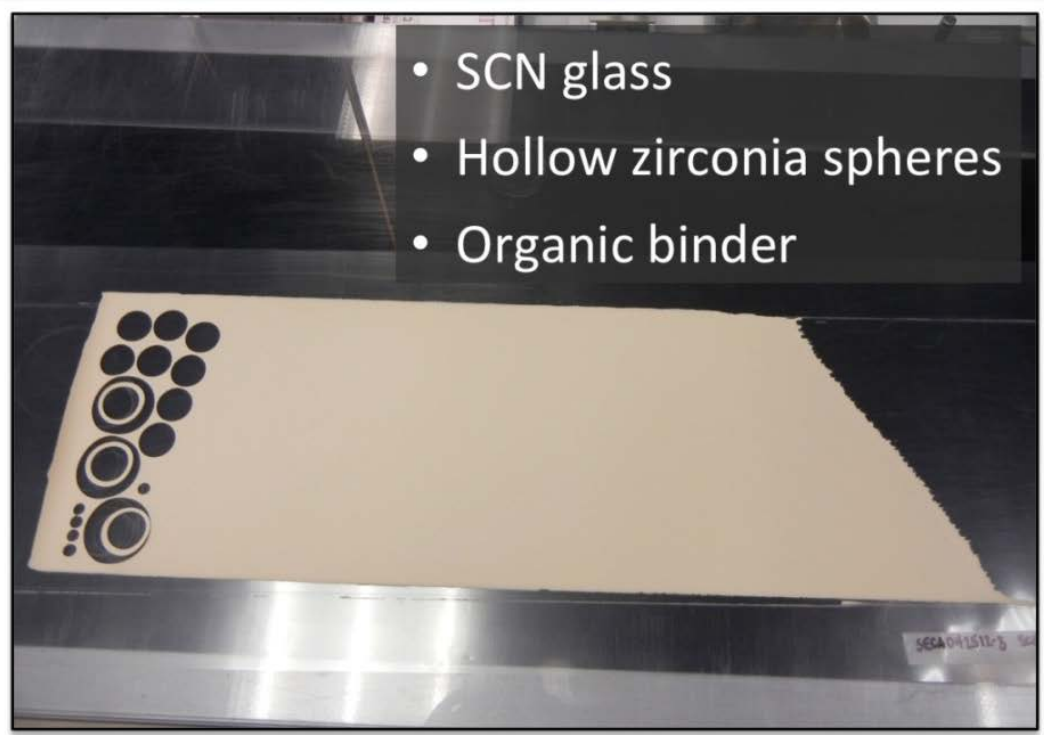

Figure 6. Photograph of a tape consisting of organic binder, hollow calcia-stabilized zirconia particles and SCN glass. 


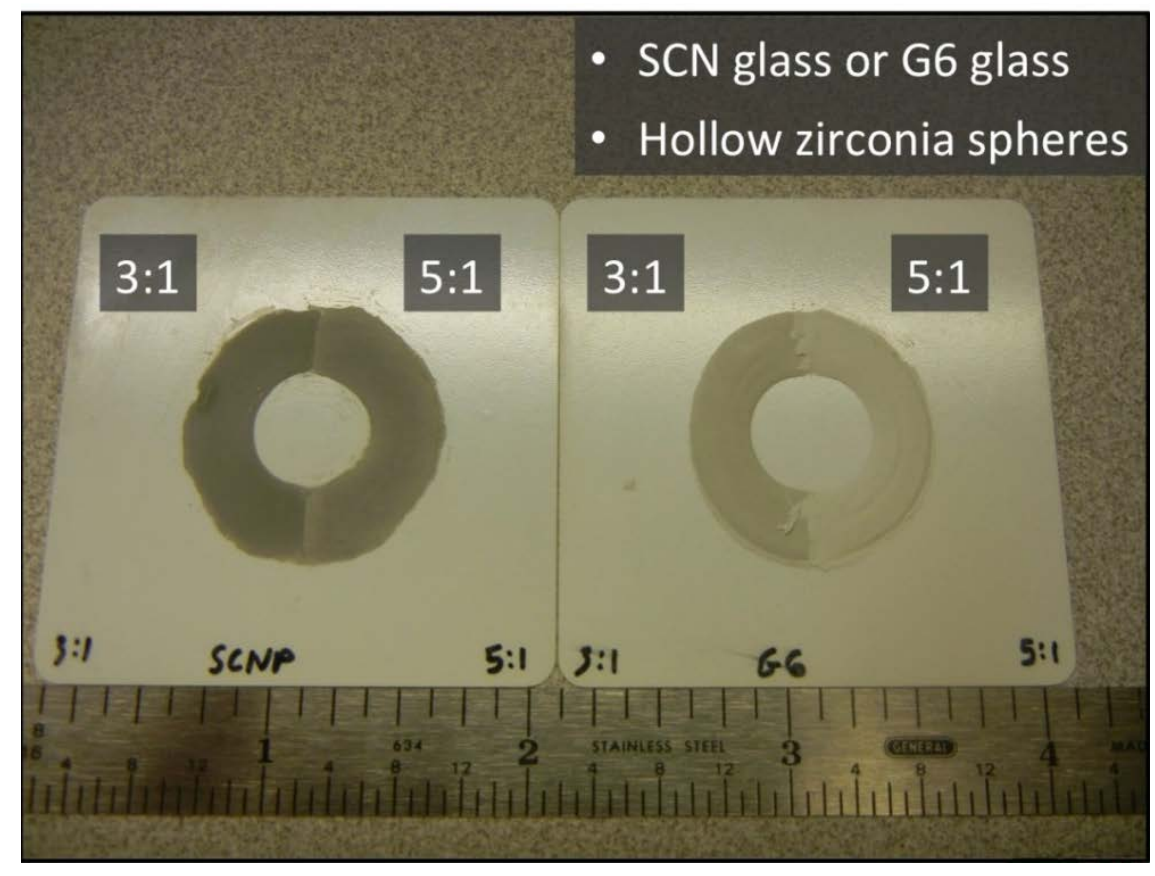

Figure 7. Two patterns of glass (SCN and G6), organic binder and ceramic particles printed onto a YSZ substrate. Each pattern contains two half-moon sections each containing different ratios of ceramic to glass particles (either $3: 1$ or $5: 1$ ).

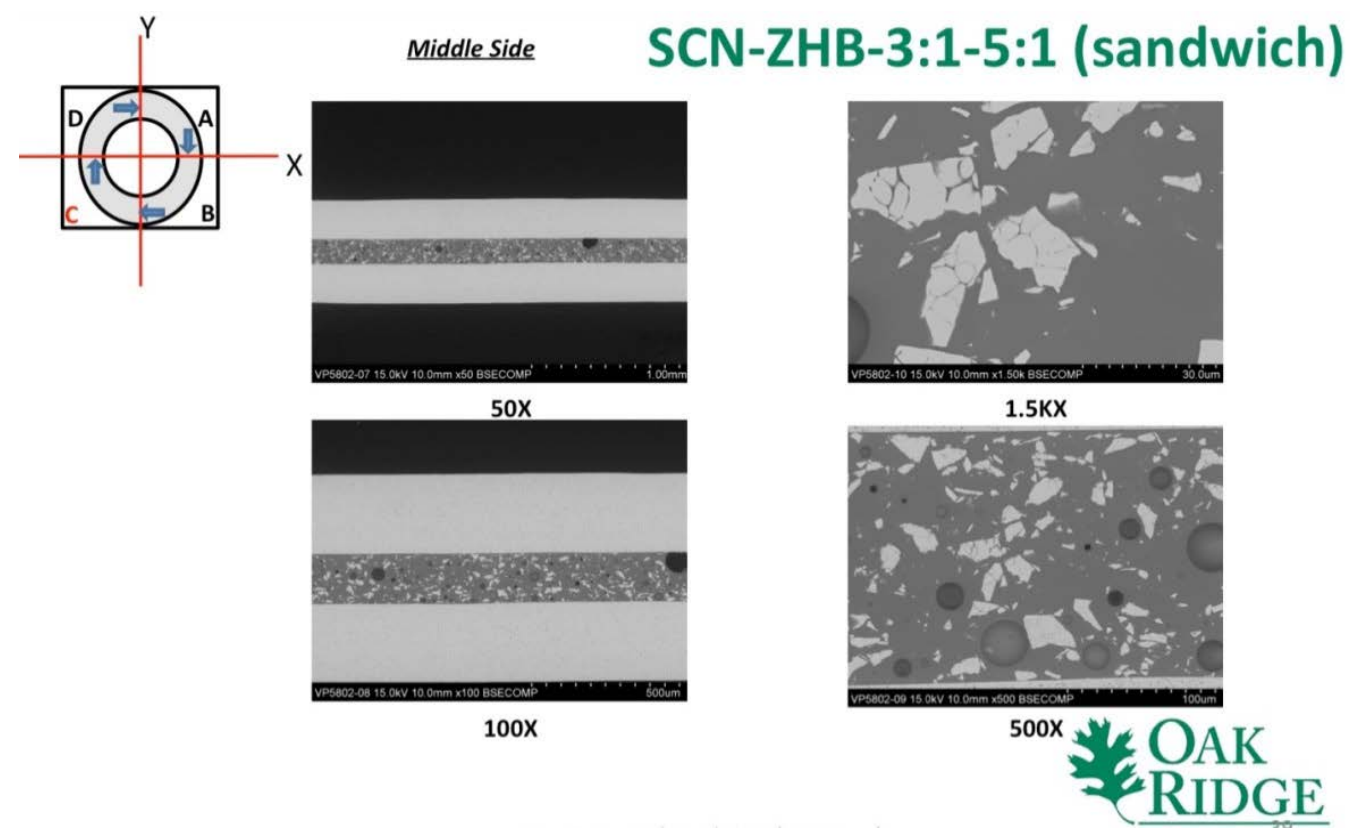

Figure 8. Cross-section of the area where the two patterns meet, demonstrating that it is possible to obtain a dense and continuous seal with different concentrations of secondary phases (in this case, frangible calcia-stabilized YSZ hollow spheres). 


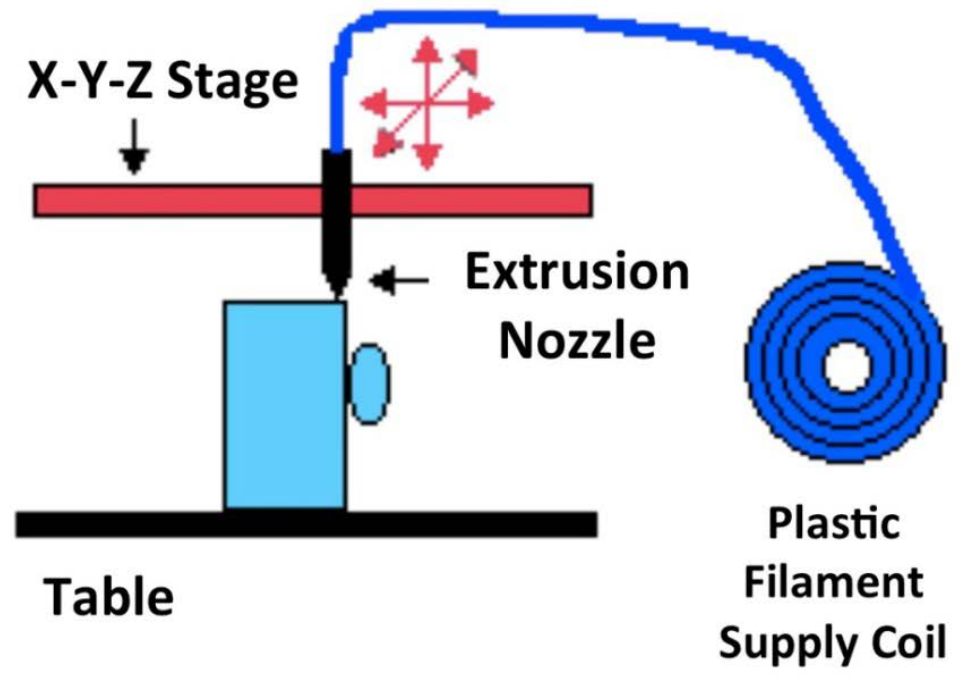

http://www.additive3d.com

Lara-Curzio et al. April 2014 (SECA Tour)

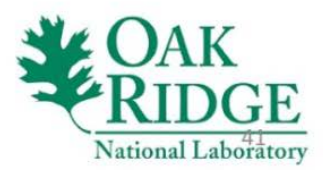

Figure 9. Schematic illustration of the fused deposition process. To obtain complex shapes, the nozzle can be moved in three axes according to a preprogrammed pattern.
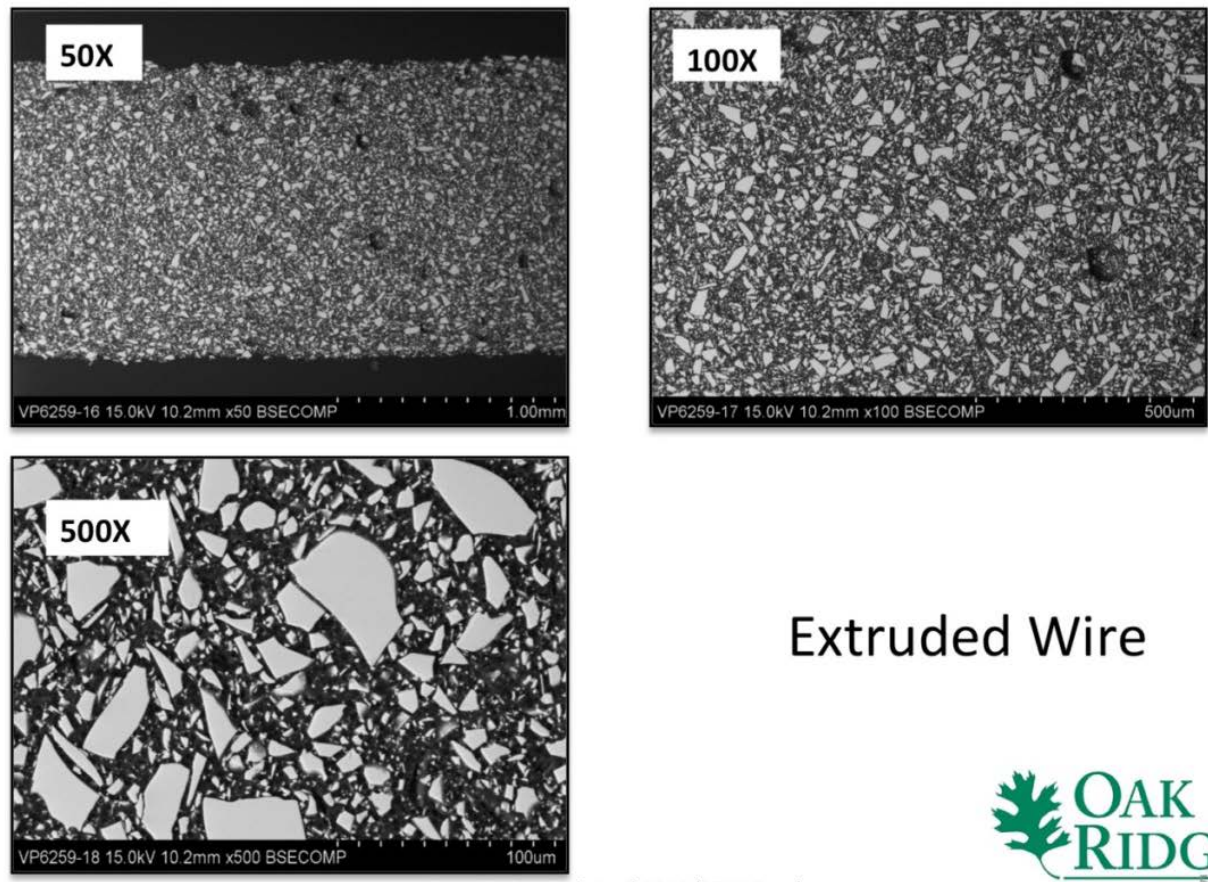

Lara-Curzio et al. April 2014 (SECA Tour)

\section{Extruded Wire}

Figure 10. Cross-section images of a wire containing $30 \%$ volume fraction of SCN glass particles embedded in a matrix of PLA. 


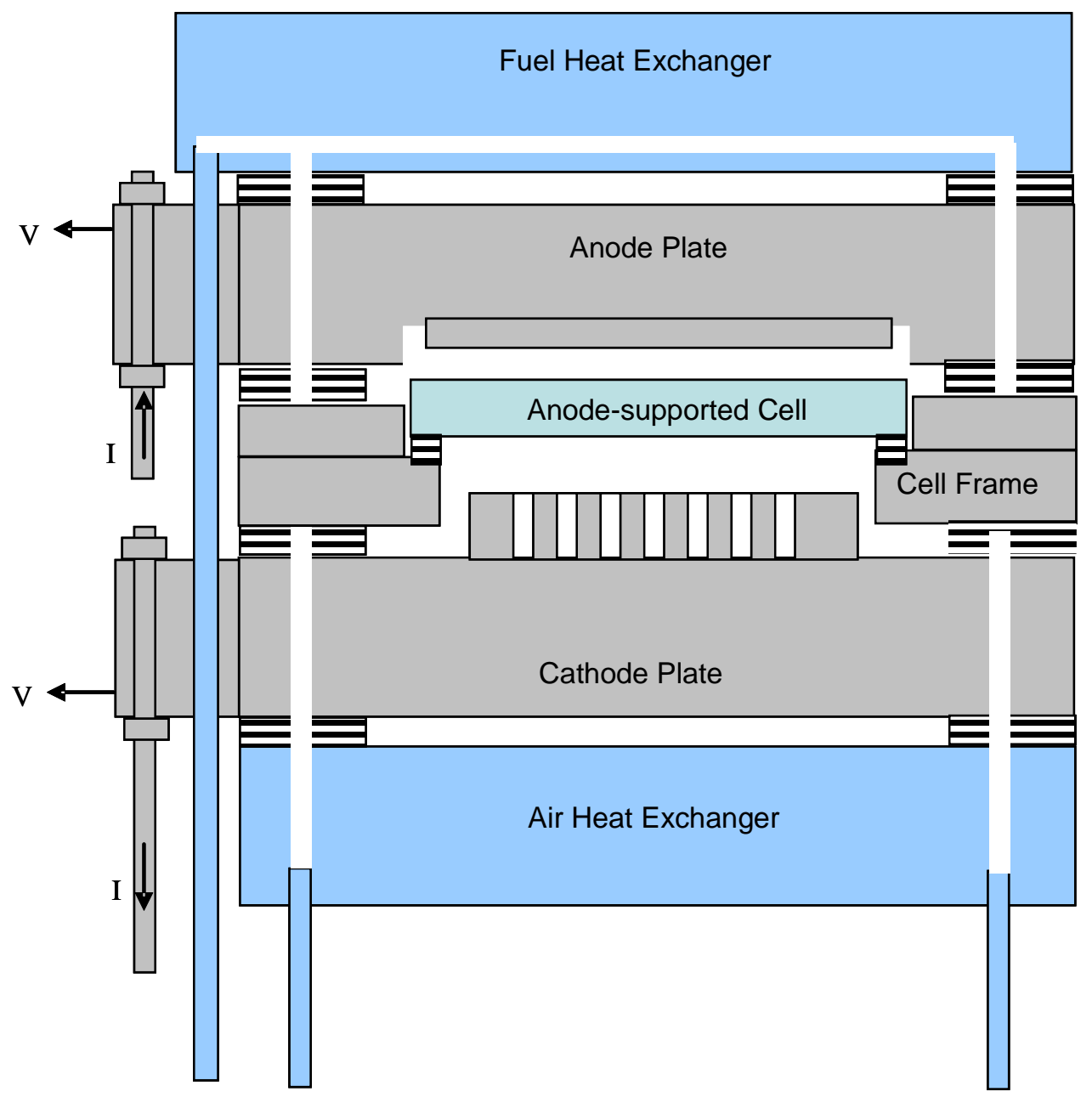

Figure 11. Schematic illustration of the SECA Core Technology Program stack test fixture (not to scale). 


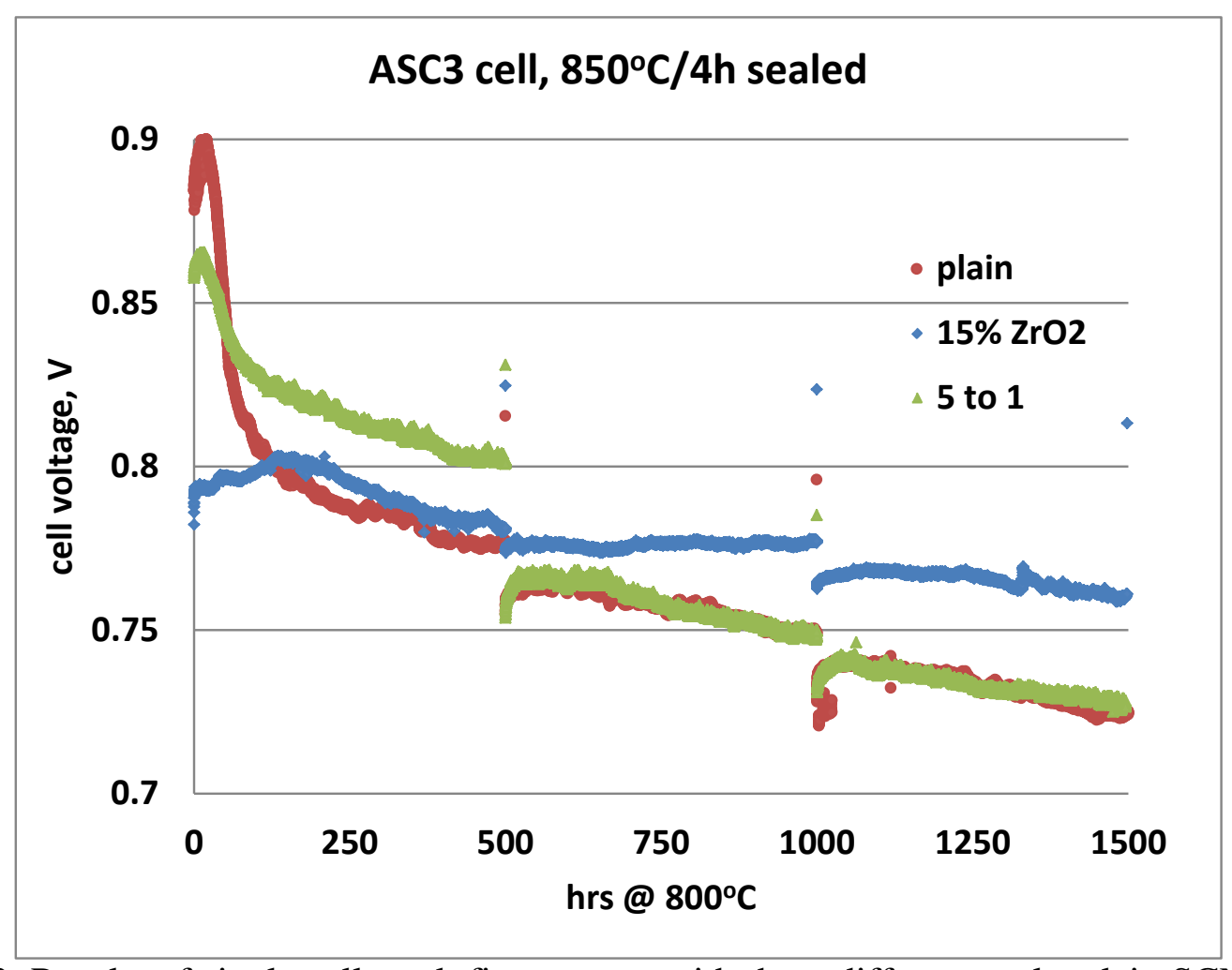

Figure 12. Results of single cell stack fixture tests with three different seals: plain SCN-1 glass, SCN-1 with 15 vol\% zirconia fiber, and SCN-1 with 17 vol\% crushed zirconia hollow spheres (5 to 1 volume ratio). The cell tests were interrupted every $500 \mathrm{~h}$ for a deep thermal cycle.

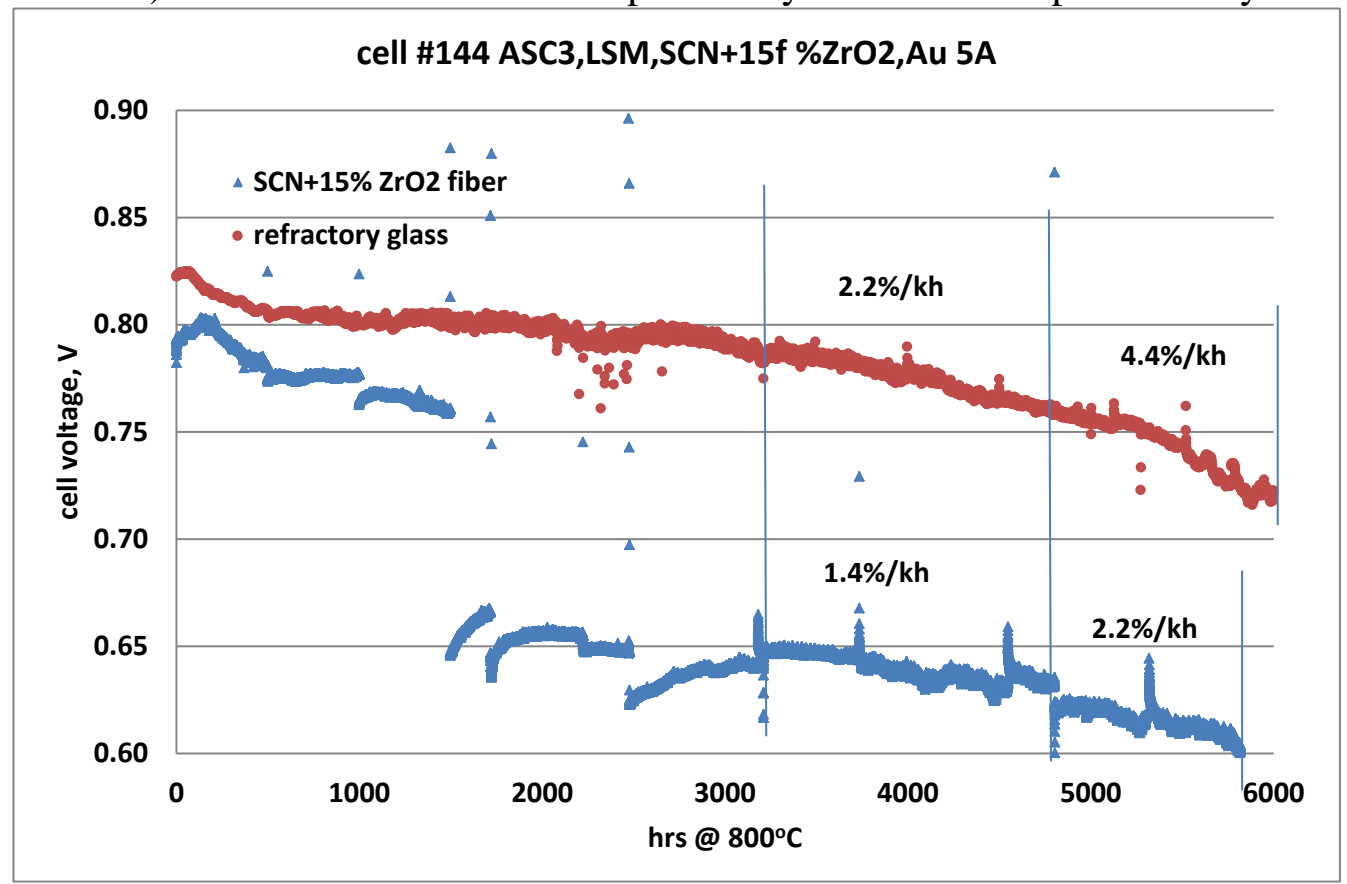

Figure 13. Long-term evaluation of an engineered compliant glass seal (SCN-1 with 15 vol\% $\mathrm{ZrO}_{2}$ fibers) in a single cell stack fixture test. 

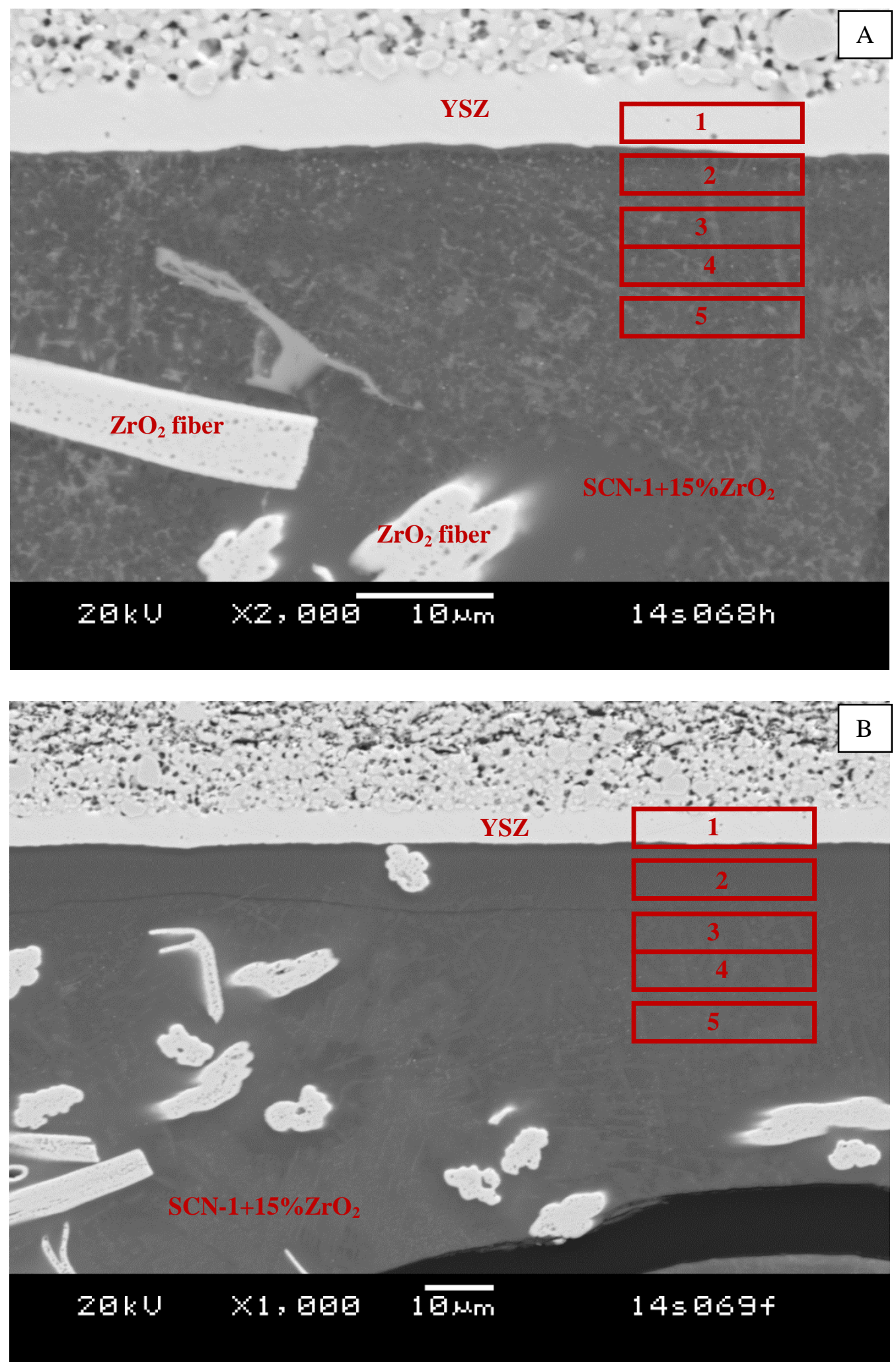

Figure 14. Typical microstructures at the seal/electrolyte interface after the long-term validation test. EDS analyses of 5 areas (\#1-\#5) are listed in Table VI. 

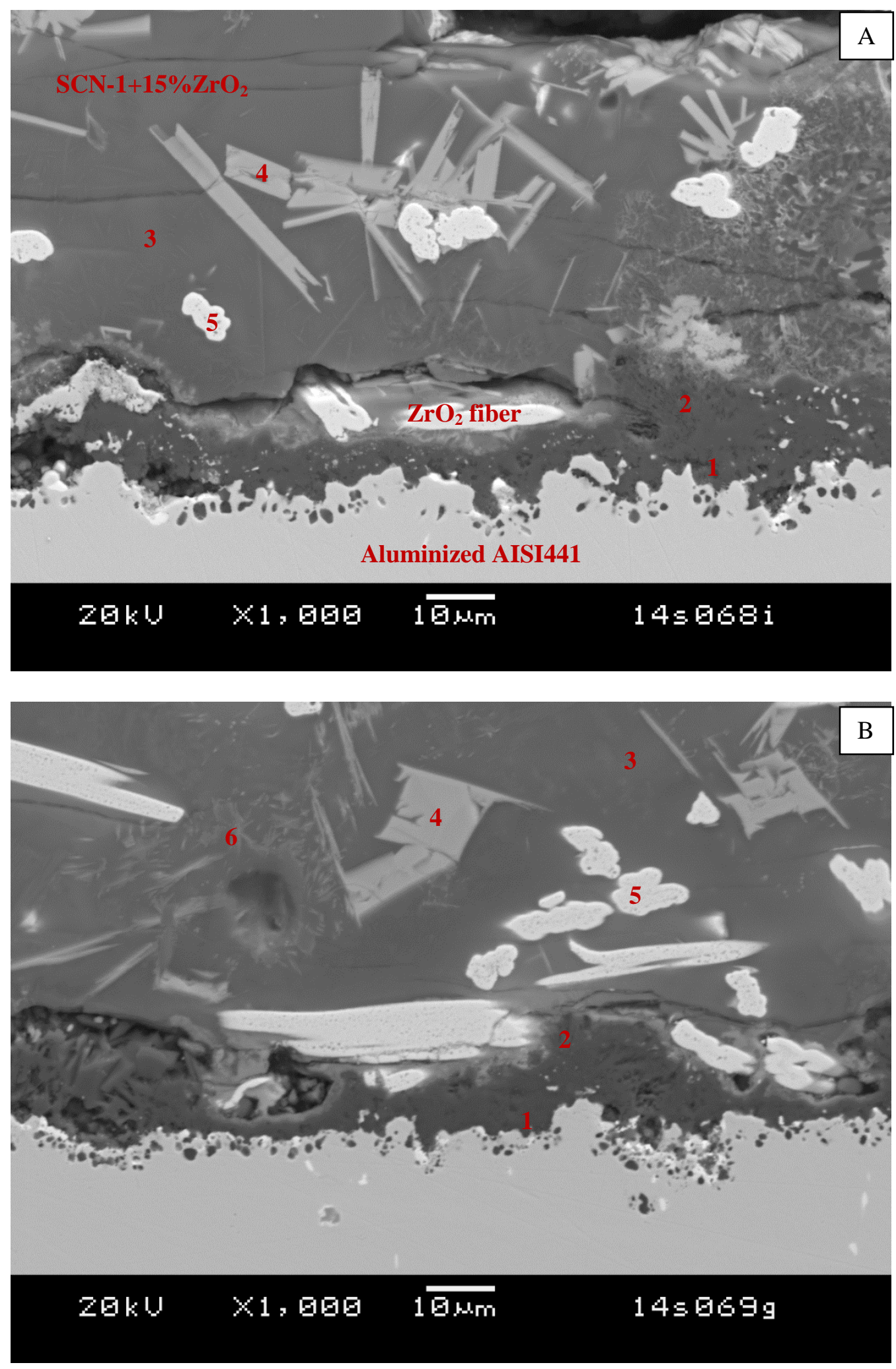

Figure 15. Typical microstructures at the seal/aluminized AISI 441 interface after the long-term validation test. EDS analyses of the indicated spots are listed in Table VII. 

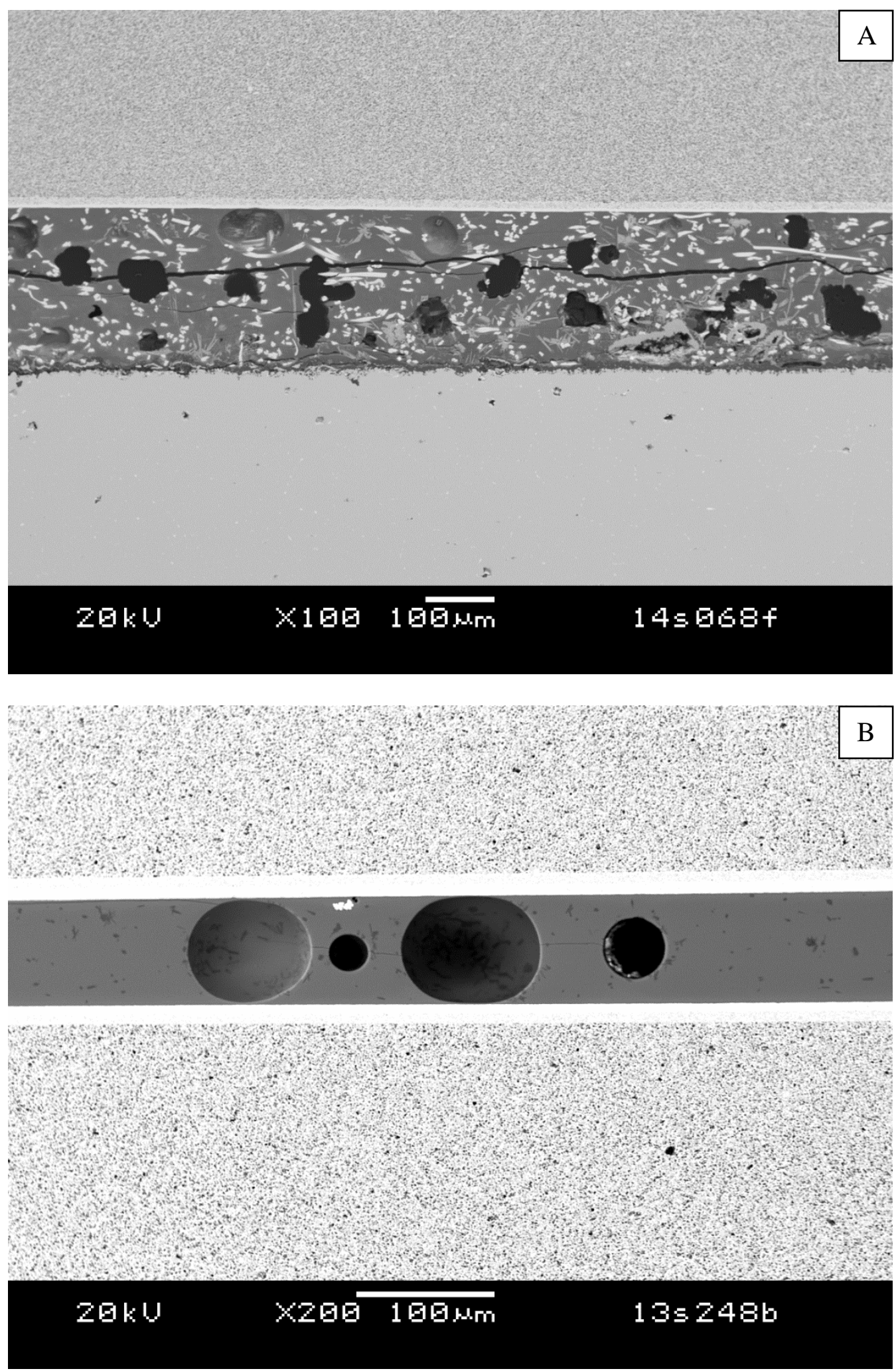

Figure 16. (A) Typical microstructure of engineered compliant glass seal (SCN-1 + 15\% zirconia fibers) after long-term stability test $\left(800^{\circ} \mathrm{C} / 5830 \mathrm{~h}\right)$; (B) plain $\mathrm{SCN}-1$ glass aged $500 \mathrm{~h}$ in air at $800^{\circ} \mathrm{C}$ between two bilayers. 


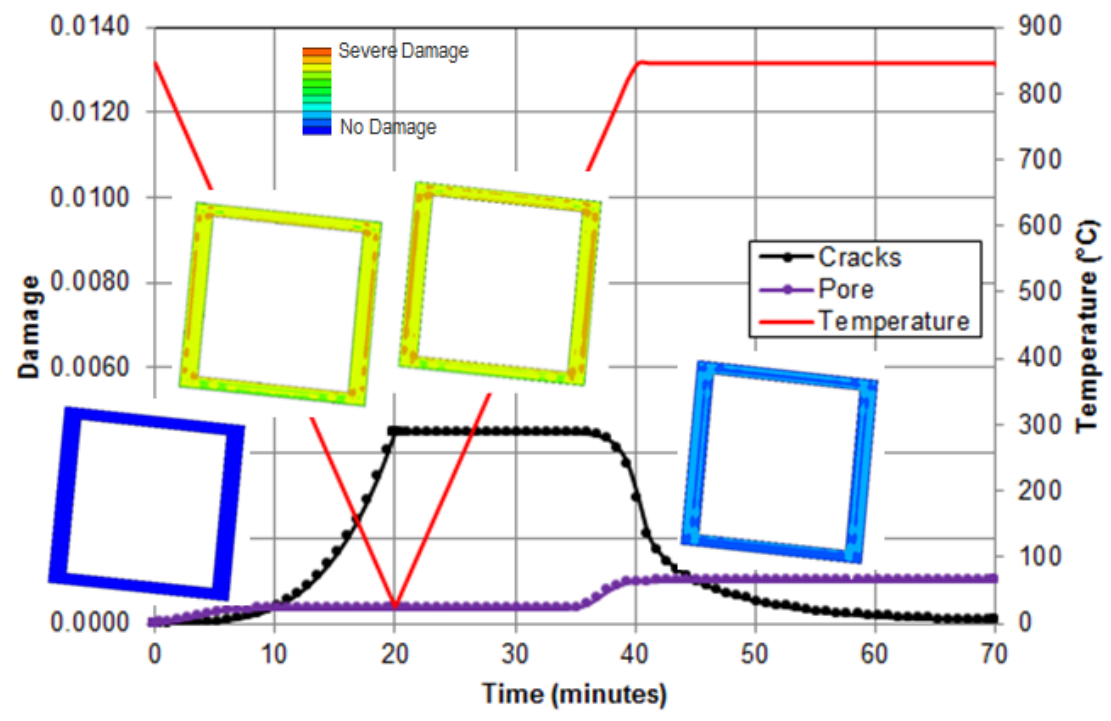

Figure 17. Transient damage distribution within the glass sealant.

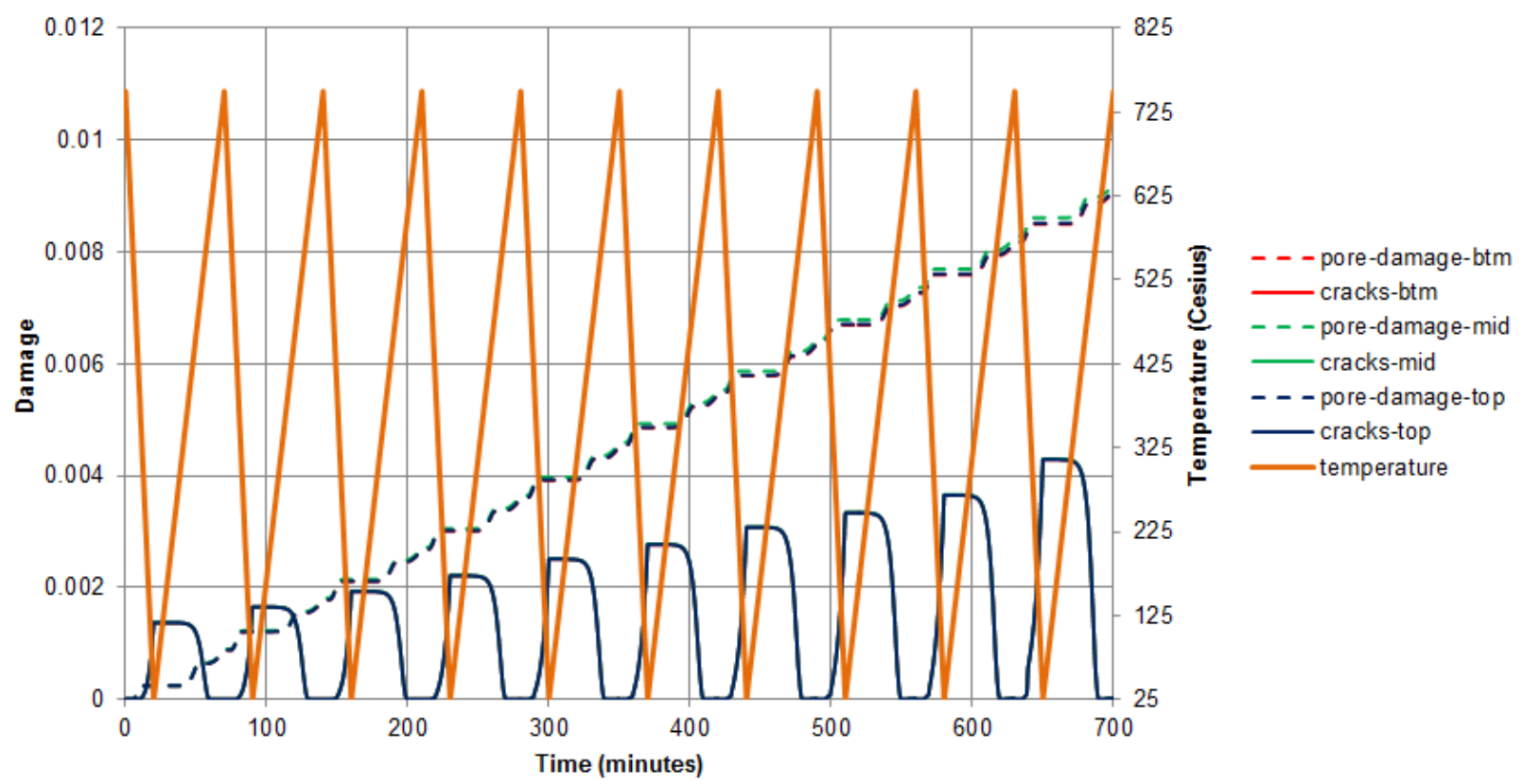

Figure 18. Damage evolution for a multi-cell PNNL stack during multiple thermal cycles. 

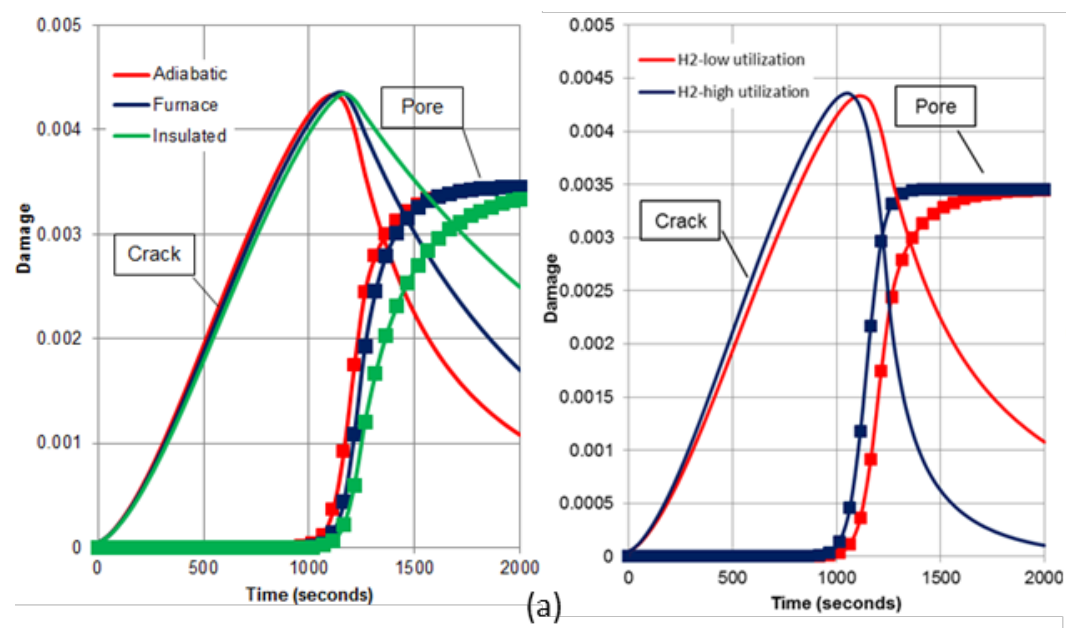

(a)

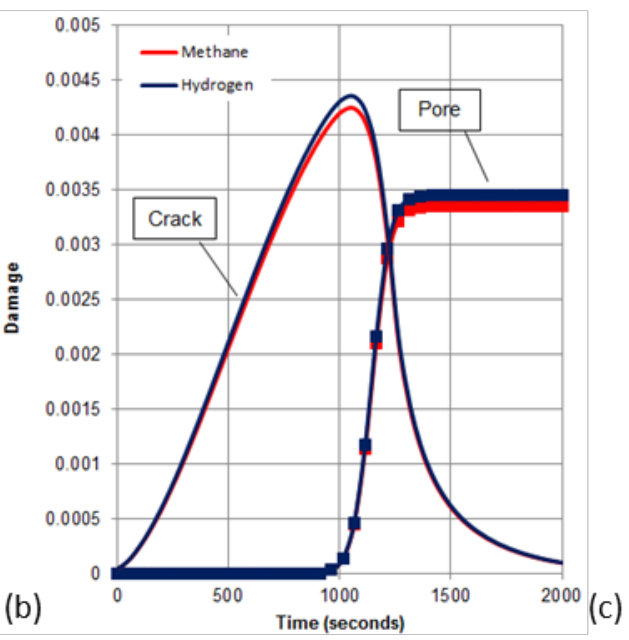

(b)

Figure 19. Effects of electrochemical operating parameters (a) thermal boundary conditions (b) power density/fuel utilization (c) fuel composition.

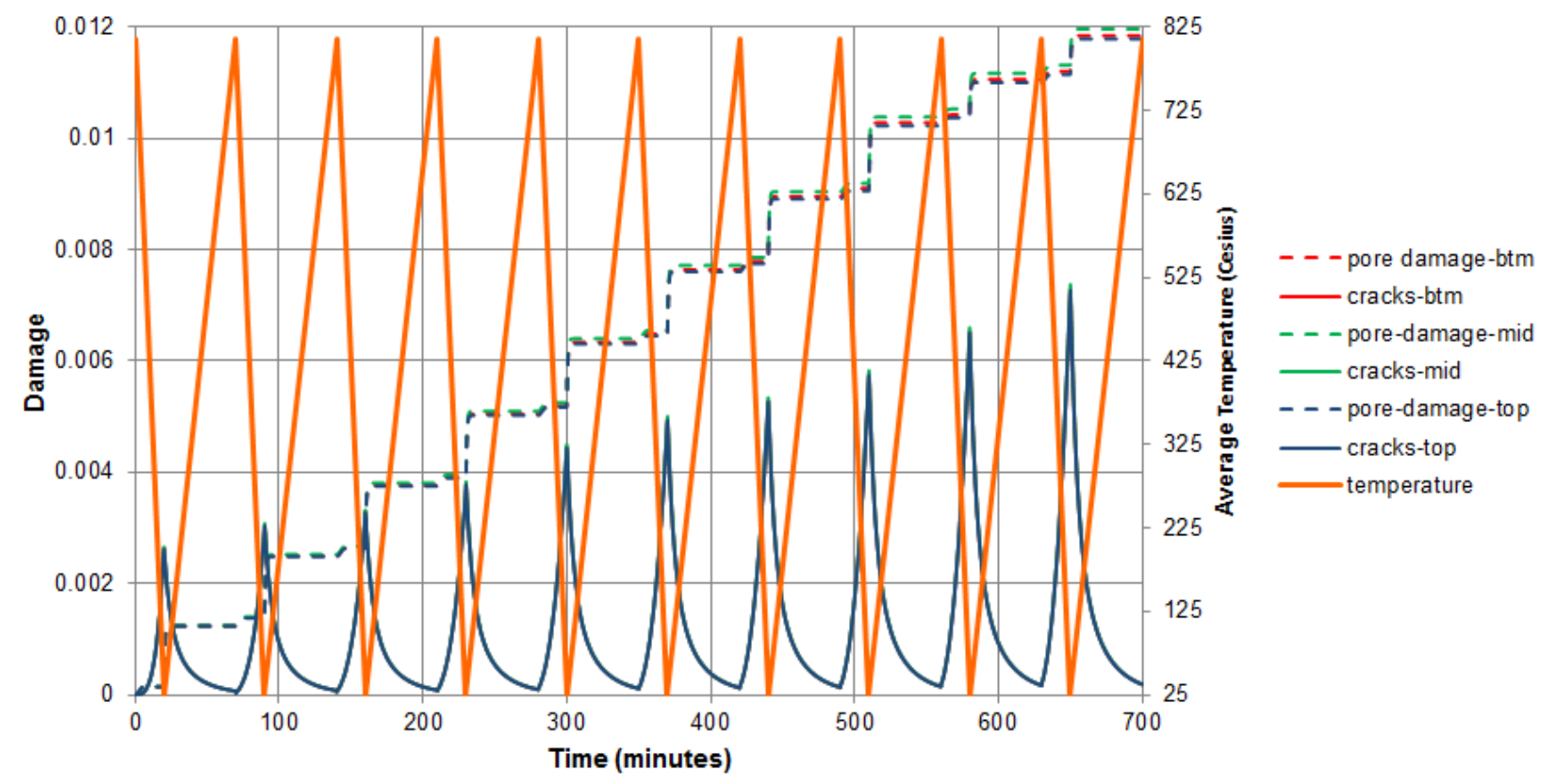

Figure 20. Damage evolution for larger multi-cell SOFC stack during multiple thermal cycles. 


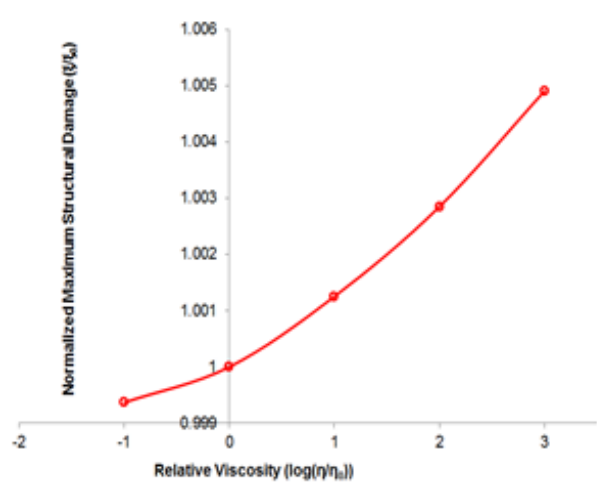

(a)

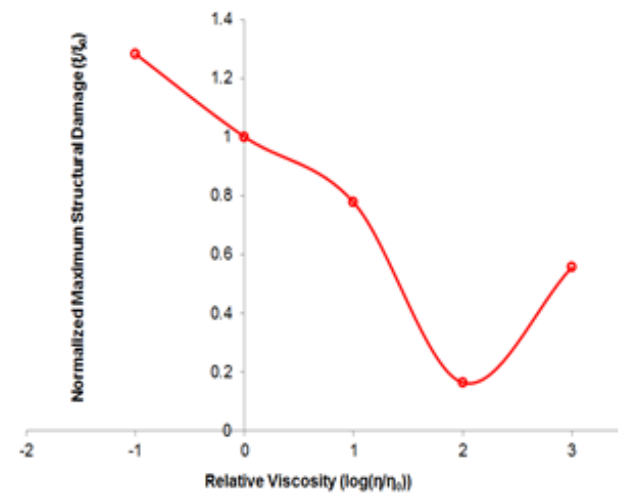

(b)

Figure 21. Effects of glass viscosity when (a) cracking or (b) pore evolution is dominant.

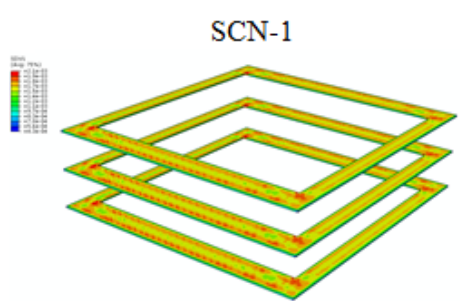

Max. Damage $=2.1 \times 10^{-3}$

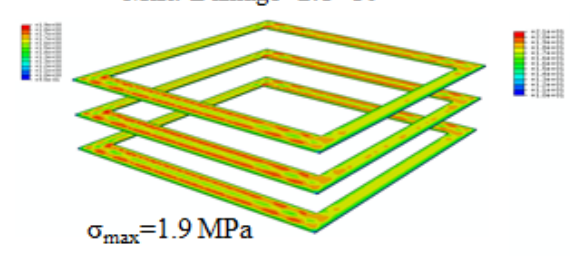

Figure 22. Comparison between SCN-1 and G18.

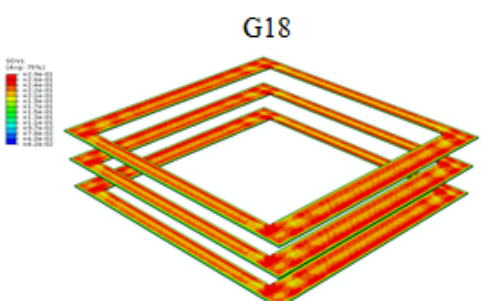

Max. Damage $=0.3$

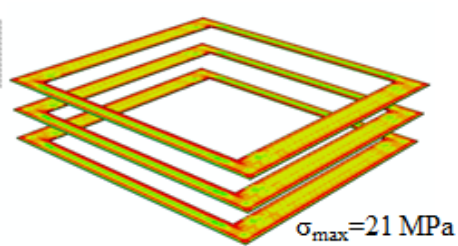




\section{Appendix: Modelling of glass seal behavior}

The temperature-dependent and rate-sensitive mechanical behavior of the compliant glass materials originates from its amorphous, liquid-like but rigidly bounded molecular structure. In order to capture the structural precursors of such immediate-range positioning symmetry and long-range conformational disorder, the overall stress response can be resolved into two components: an equilibrium time-independent stress element accounts for the entropic molecular configuration rearrangement, while an inelastic history-dependent stress element is assumed to describe the stiff macroscopic deformation due to the enthalpic stretching of intermolecular and intramolecular bonds. The one-dimensional rheological analog shown in Figure A1 is used to illustrate such a thermo-viscoelastic concept with the Maxwell component capturing the viscous response and the parallel linear Hookean spring representing the elastic characteristic. The following constitutive model description summarizes the development described in [1].

The deformation can be decomposed into thermal and mechanical parts as $\vec{\varepsilon}=\dot{\varepsilon}_{T}+\dot{\varepsilon}_{M}$ with the latter further split into the elastic and viscous components as $\dot{\varepsilon}_{M}=\dot{\varepsilon}_{e q}=\dot{\varepsilon}_{n e}+\dot{\varepsilon}_{v}$ where

$\boldsymbol{\varepsilon}_{T}=\alpha(T)\left(T-T_{0}\right) \boldsymbol{I}$ describes the isotropic thermal expansion, $\boldsymbol{\varepsilon}_{M}$ denotes the mechanical strain, $\boldsymbol{\varepsilon}_{\boldsymbol{\theta} q}$ measures the equilibrium atomic packing coordination, and $\boldsymbol{\varepsilon}_{n \boldsymbol{e}}$ and $\boldsymbol{\varepsilon}_{v}$ correspond to the non-equilibrium elastic and viscous deformation, respectively.

The constitutive relations then yield $\dot{\sigma}_{M}=\dot{\sigma}_{v}+\dot{\sigma}_{e q}$ with $\dot{\sigma}_{e}=(1-\varphi) C_{e q}: \dot{\varepsilon}_{e q}$, $\dot{\sigma}_{v}=(1-\varphi) \boldsymbol{C}_{n e^{3}} \cdot \dot{\boldsymbol{\varepsilon}}_{n e}$, and $\boldsymbol{\sigma}_{v}=\mu(T) \dot{\varepsilon}_{v}$. Here, $\boldsymbol{\sigma}_{M}$ represents the overall mechanical response, $\boldsymbol{\sigma}_{v}$ defines the non-equilibrium stress acting on the viscoelastic component, $\sigma_{e q}$ characterizes the equilibrium stress, and $\boldsymbol{C}_{e q}$ and $\boldsymbol{C}_{n e}$ denote the isotropic elasticity tensors.

The temperature dependence of the material viscosity $\mu(T)$ can be described by the VogelFulcher-Tammann (VFT) equation $\log \mu(T)=\log \mu_{0}+\frac{A}{T-T_{v}}$ where $\mu_{0}$ is the reference viscosity, $A$ is a material constant, and $T_{v}$ is the Vogel temperature representing the ideal glass transition temperature at which flow can no longer occur and the free volume drops to zero.

Since the deterioration and recovery in glass materials typically refers to the formation, accumulation, and reduction of mechanical cracks and internal pores, the scalar damage variable $\varphi$ can then be divided into $\dot{\varphi}=\dot{\varphi}_{c}+\dot{\varphi}_{p}$ where $\varphi_{c}$ and $\varphi_{p}$ account for the damages induced by cracks and pores respectively. To be inclusive, they can be generally written as $\dot{\varphi}_{c}=\dot{\varphi}_{c}^{n}+\dot{\varphi}_{c}^{g}+\dot{\varphi}_{c}^{h}$ and $\dot{\varphi}_{p}=\dot{\varphi}_{p}^{n}+\dot{\varphi}_{p}^{g}+\dot{\varphi}_{p}^{h}$, in which the superscripts $n, g$, and $h$ represent the terms of nucleation, growth, and healing, respectively.

For a randomly oriented micro-crack filled solid medium in which the micro-crack nucleates under critical stress, the crack nucleation can be interpreted as $\dot{\varphi}_{c}^{n}=\lambda \Sigma^{m} \Sigma^{n}$ where $\Sigma$ denotes the first stress invariant, $\lambda$ refers to the proportionality constant, and $m$ factorizes the load effects. Moreover, since crack growth is mainly driven by the change of the elastic energy, its propagation can be captured by $\dot{\varphi}_{c}^{g}=\frac{\frac{\partial \sigma_{V}}{\partial \varphi_{c}} \dot{\varepsilon}_{n e}+\frac{\partial \sigma_{B Q}}{\partial \varphi_{e}} \varepsilon_{\varepsilon q}}{\frac{\partial F_{c}\left(\varphi_{c} T\right)}{\partial \varphi_{c}}}$ where the damage threshold function $F_{c}\left(\varphi_{c}, T\right)$ characterizes the critical energy state for the cracking and can be numerically determined from the experimental stress-strain curves as shown in Figure A2.

The self-healing morphological changes of the cracked compliant glass at elevated temperatures such as blunting and pinching of crack tips, rounding and grooving of radial cracks, receding and breaking up of lateral and median cracks that later turn into cylindrical or spherical closed cavities and ultimately disappear are believed to be driven by the combined viscous flow- and diffusional mass transport. In other words, the whole crack healing process essentially consists of two locally sequential phenomenological stages: 1) the geometrical crack closure induced by the creep deformation and 2) the re-establishment of the physical bonding across the crack interface due to the surface diffusion. The 
former is captured by the material viscous flow behavior, while the latter is determined from the lowerlength scale simulation, specifically, the kinetic Monte Carlo (kMC) model.

As a typical computational tool in simulating the time evolution of natural physical processes, the $\mathrm{kMC}$ model is naturally effective to describe the inter-diffusion healing stage in the current study. Figure A2 shows the $(\mathrm{M} \times \Delta \mathrm{S}) \times(\mathrm{M} \times \Delta \mathrm{S}) 2 \mathrm{D}$ lattice model used in the kMC simulation, where the nondimensional lattice spacing is denoted by $\Delta \mathrm{S}$. If $\Delta \mathrm{x}$ takes the covalent bond length of the glass, the model then actually represents a specimen with an already closed but not healed crack. Convergence studies further demonstrate that $\mathrm{M}=1000$ is able to ensure sufficient prediction accuracy.

The healing probability of an arbitrary bond follows $P=\omega_{k} \cdot \exp \left(\frac{-E_{k}}{k T}\right)$ where $k$ is Boltzmann constant, $\omega_{h}$ is the frequency and $E_{h}$ is the activation energy. The model is then calibrated by controlled healing experiments where two rectangular SCN-1 glass bars with dimensions of $4 \mathrm{~mm} \times 3 \mathrm{~mm} \times 23 \mathrm{~mm}$ were placed vertically in a fixture as shown in Figure A3(a) and exposed to different elevated temperatures for varying time periods before being taken out for flexural strength measurements following ASTM C1161-02 (Figure A3(c)). Since no gap is left between the specimens, the two bars together can be perceived as one SCN-1 glass bar of double length but with an already closed crosssectional crack in the middle of the span. The healing experiments actually record the fracture surface inter-diffusion and physical bonding re-establishment evolution in the healing stage. The scale damage variable $\varphi$ is determined by the ratio of the total of remaining broken bonds to the initial amount of broken bonds in the kMC model and by the measured flexural strength divided by that of the virgin glass in the experiments. In that way, the probability function for the $\mathrm{kMC}$ model was then calibrated and the temperature dependence of the crack healing rate could be formulated as $\dot{\varphi}_{c}^{h}=-\exp (\vartheta T+\varsigma) \varphi_{c}$. Here, $\vartheta$ and $\varsigma$ are temperature dependent parameters. Since $\dot{\varphi}_{c}^{h}$ drops exponentially with the decrease in $T$, there could be a lower bound temperature below which no observable healing would occur within any practical time frame.

Since pore accumulation is commonly perceived as the main phenomenon associated with the inelastic deformation process which generally originates from the simultaneous growth of both preexisting interstitial voids and the newly nucleated cavities at the internal imperfection sites, a general equation for pore nucleation can be given as $\dot{\varphi}_{p}^{n}=\chi\left(\frac{\exp \left(\frac{\omega\left|\Sigma-Z_{n}\right|}{k T}\right)-1}{1-\varphi_{p}}\right)$ to capture the most significant thermally-activated, sub-microscopic, imperfection induced, and homogeneous pore nucleus formation mechanism under diffusion. $\chi$ represents the coalescence effect and $\omega\left|\Sigma-\Sigma_{n}\right|$ describes the nucleation energy barrier with $\Sigma_{n}$ denoting the threshold hydrostatic stress and $\omega$ weighing the stress influence. Furthermore, due to mass conservation, the growth of the internal pores yields $\dot{\varphi}_{p}^{g}=\left(1-\varphi_{p}\right) \xi \operatorname{tr}\left(\dot{\varepsilon}_{v}\right)$ where $\xi$ is typically considered as a constant describing the compressibility of the matrix material. As no pore healing has been observed in experiments, $\dot{\varphi}_{p}^{h}$ is neglected.

The present glass material damage-healing model is then implemented into finite element analyses through commercial engineering software ABAQUS user subroutines to simulate the thermomechanical performance of the glass sealant within the SOFC stacks. Although geometrical features or specifics may vary between different SOFC stacks, the essential mechanical components are typically the same, including the interconnect plates, PEN, glass seal, and metallic window frame. Sequentially repeating the cell units between two heat exchanger/compression blocks then forms the multi-cell SOFC stack. Figure A5 shows the finite element model of an in-house three-cell SOFC stack that has been tested, in which the cells are separated by window-frames and interconnect plates made of SS441 stainless steel, and the compliant glass seal is applied to attach the cell to the window-frame.

Numerical simulations were then performed to predict the structural response of this multi-cell SOFC stack when exposed to deep thermal cycling loads. The stack is simply supported at the bottom with slight compressive load on the top as suggested by the experiments. During a rapid cooling-heating cycle, the ambient temperature decreases from the normal operating temperature to the room temperature in 20 minutes and then bounces back in 50 minutes. This procedure has repeated for a total of 10 cycles. 
Figure A6(a)-(d) show the contours of the transient stress and damage distribution over the three seals. It is found that all of the seals appear to result in almost identical thermo-mechanical loading and degradation conditions. As the most degraded areas coincide with the locations of stress concentrations, it indicates and verifies the speculation that the cooling-induced mechanical mismatch is primarily responsible for damage. However, the predicted results also show that even under such aggressive thermal loading circumstance, the overall structural damage is still trivial and within the expected tolerance for development of a possible leak path, demonstrating the effectiveness of the novel SCN-1 glass.

Besides the damage typically concentrating near the edges, it is also noticed that the seal attached to the middle cell shows slightly higher degradation than the other two, which is relatively more revealing in the porosity distribution contour. It could be caused by the double mechanical constraints that the middle cell has to comply with from the top and bottom interconnects. Such effects may be even more pronounced in a larger stack size.

The time evolution of the average damage along with the temperature profile is shown in Figure A7. It can be seen that the amount of damage induced by porosity starts lower than that caused by mechanical cracking especially during the first 1 or 2 cycles. However, unlike the cracking damage that can be healed every time upon heating, the pores occupied by the entrapped air bubbles are prevented from annealing. Therefore, as thermal cycling continues, the glass sealant material keeps being further degraded, which makes it increasingly easier for cracks to initiate and accumulate as demonstrated by the predicted results for the subsequent loading cycles.

Since the electrochemical reactions occurring within the cell typically have prominent influence on the working temperature environment of the SOFC stack, its effects on the long-term functionality and reliability of the compliant glass sealant has also been investigated by integrating the FEM analyses with the PNNL-developed SOFC-MP multi-physics calculations.

A $10 \times 10 \mathrm{~cm}$ industrial characteristic co-flow SOFC single-cell stack is used in the numerical simulations, in which the fuel and air enter from the left side at a temperature of $700^{\circ} \mathrm{C}$. Crucial parameters such as fuel utilization, fuel composition, and thermal boundary conditions, i.e. adiabatic, furnace, and insulation have been examined. Here two types of fuels, specifically wet hydrogen and a reforming composition containing methane, have been considered. For the adiabatic condition, no heat transfer is allowed between the SOFC stack and its surroundings; for the furnace condition, the SOFC stack is assumed to be placed in a constantly heated furnace; and the insulated condition describes a SOFC stack in an enclosure container made of low thermal conductivity insulation materials whose outer boundaries are kept at room temperature.

Figure A8 shows the temperature maps that correspond to different fuel utilization and composition conditions, where it can be seen that high fuel-utilization operation leads to the largest temperature gradient over the stack. Similar plots for the temperature profiles yielded by different thermal boundary conditions are also presented in Figure A9. Unlike the adiabatic condition where the temperature monotonically increases from the left to right, the furnace and insulated conditions appear to localize the heated zones within the central region with temperatures decreasing radially outwards. It is also noticed that furnace and insulated conditions generally result in lower temperature fields and narrower temperature gradients.

The resultant damage evolution behaviors as responses to the CTE-mismatch induced thermal stresses have been shown in Figure A10. Although the SOFC stacks under adiabatic, furnace, and insulated conditions behave quite similarly, non-adiabatic cases tend to show slightly lower pore damage and slower healing because of the cooler internal environment. Similar behavior was also observed for different fuel utilizations as aggressive high power operation yields larger temperature gradients which can introduce more stress concentrations and damage. The difference between methane-powered and hydrogen-powered SOFCs appears to be trivial for these cases, although the comparatively more uniform temperature field for methane produces slightly lower mechanical degradation.

As one of the most important physical properties in the glass, viscosity can substantially affect the material's mechanical behaviors. However, unlike the elastic modulus of which the increase promotes the 
damages due to the intensified stress field, the glass viscosity influences the damage response in a mechanism-dependent manner. Figure A11(a)-(b) show the predicted variation of damage with viscosity for cases where different damage sources dominate. It is found that, when cracking is dominant, higher viscosity results in more damage because of the hindered stress relaxation; while when pore evolution is dominant, increasing viscosity will reduce damage by preventing the flow driven pore coarsening until a limiting viscosity corresponding to the rise of the stress concentration effect is met. These findings could potentially reconcile the contradictive experimental observations reported in the open literature $[2,3]$ and will also provide guidance to material customizations, i.e. addition and dispersion of reinforcement phase such as ceramic fibers/particles to mitigate pore coarsening.

Since such material strengthening customization is likely to introduce non-uniform material properties, further studies have been conducted to evaluate such heterogeneity effects. As shown in Figure A12, a distribution of viscosities has been considered within the glass sealant with the specific properties of material points randomly assigned.

It is found in Figure A13 and A14 that the non-uniform viscosity field can strongly elevate the mechanical resistance of the glass seal. It can be seen that both average cracking damage and pore growth are sharply reduced. A wider damage peak appears in the crack evolution probably because of the scattered material properties. After further examining the stress conditions, it was demonstrated that the relaxation of stress in the inhomogeneous configuration is the essential driving force for the drastic damage reduction.

Furthermore, a compliant glass mechanical response in terms of characteristic material properties, i.e. elastic modulus and viscosity has been established in Figure A15 where the relative deviations of the material properties that describe the heterogeneity fall into the range of $1 \mathrm{e}-2$ to $1 \mathrm{e} 2$. It can be observed that cracking damage is highly sensitive to stiffness but less affected by viscosity, while pore growth is strongly influenced by both characteristics. It is thus concluded that an optimal material design configuration with a high viscosity and low stiffness would be most likely to result in the lowest overall damage. Tailored material properties through the addition of reinforcement phases could help to achieve such a desirable property combination.

\section{References}

[1] W. Xu, X. Sun, B.J. Koeppel, H. Zbib, International Journal of Plasticity, submitted, (2014).

[2] Y.I. Kim, D.H. Lee, W.J. Kim, S. Park, H.N. Kim, D.B. Lee, J.C. Lee, Reviews on Advanced Materials Science, 28 (2011) 111-115.

[3] D.B. Lee, M.J. Choi, S. Park, J.C. Lee, Journal of Nanoscience and Nanotechnology, 13 (2013) 628631. 


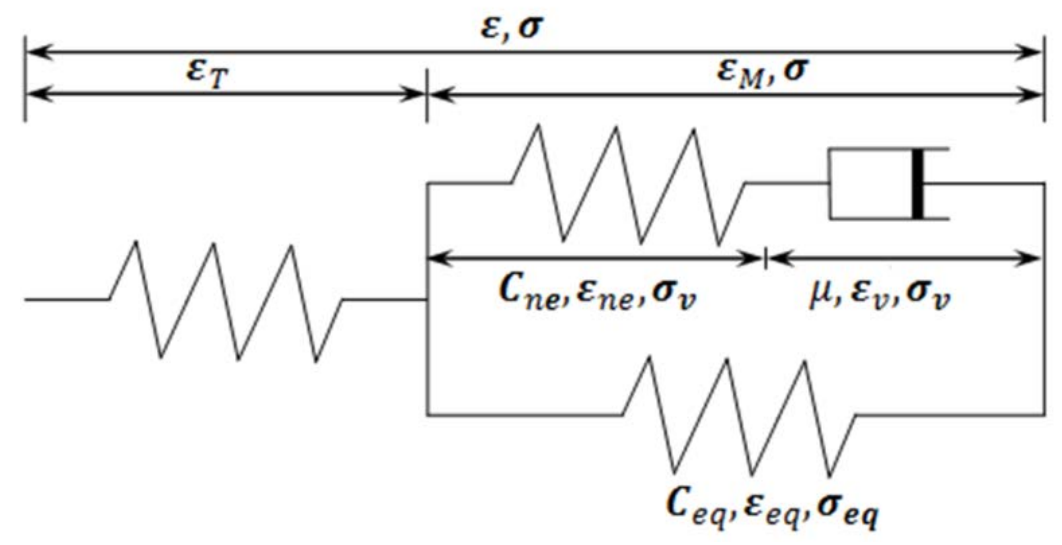

Figure A1. Linear analog of the thermo-inelastic model
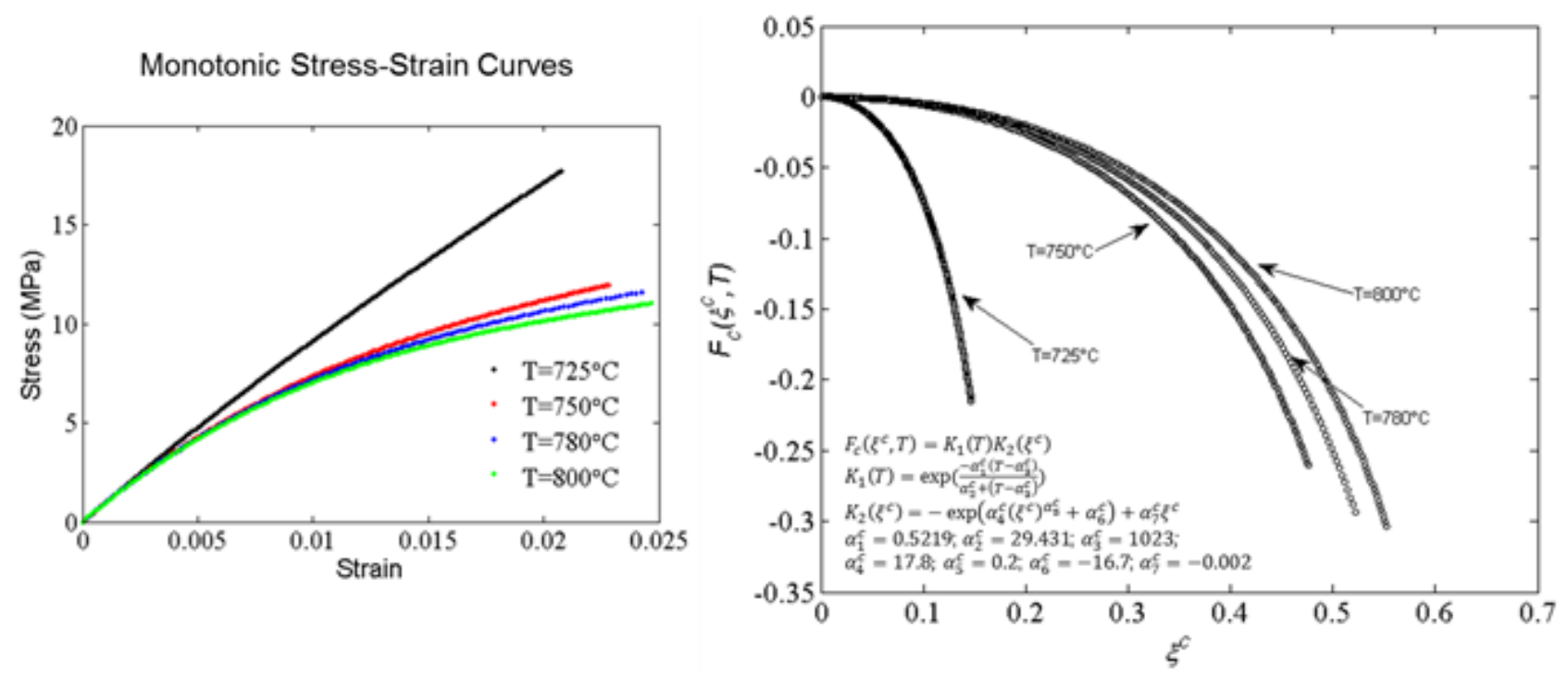

Figure A2. Experimental calibration of crack propagation kinetics 

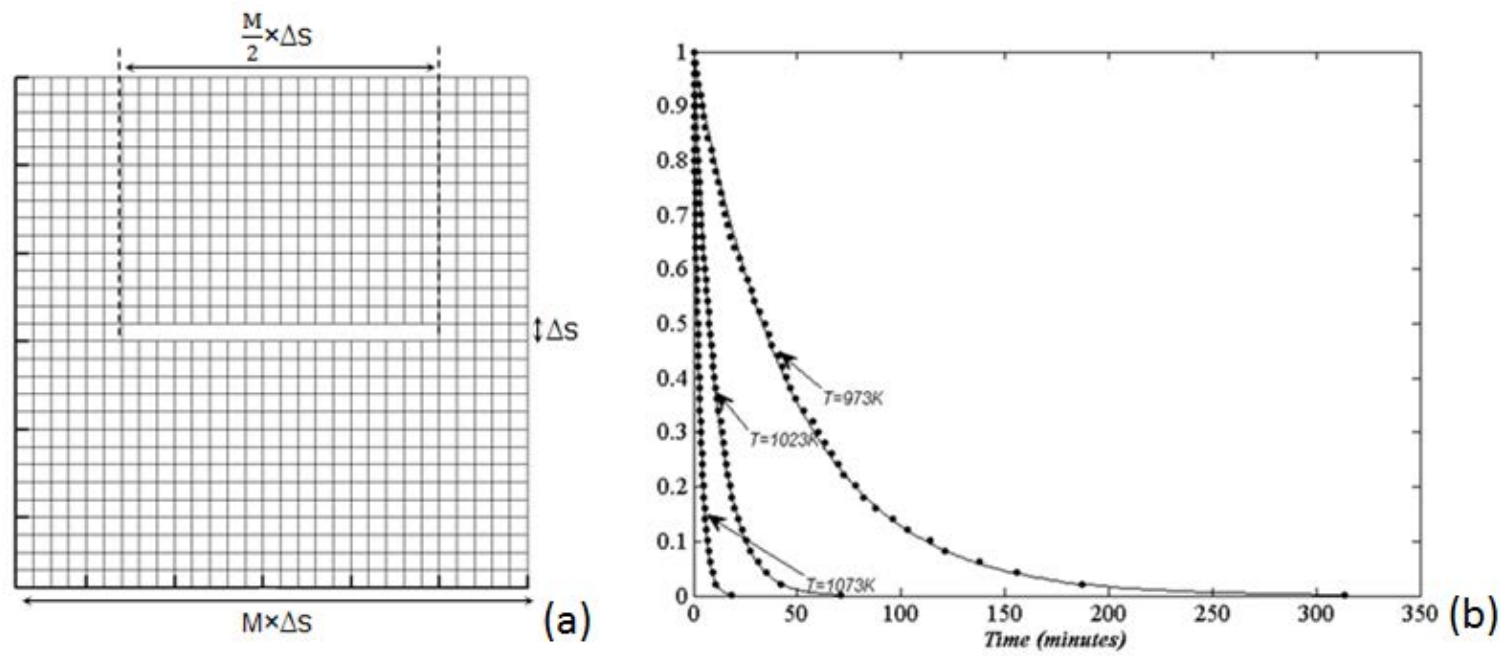

Figure A3. (a) illustration of $\mathrm{kMC}$ model (b) $\mathrm{kMC}$ prediction of crack healing kinetics
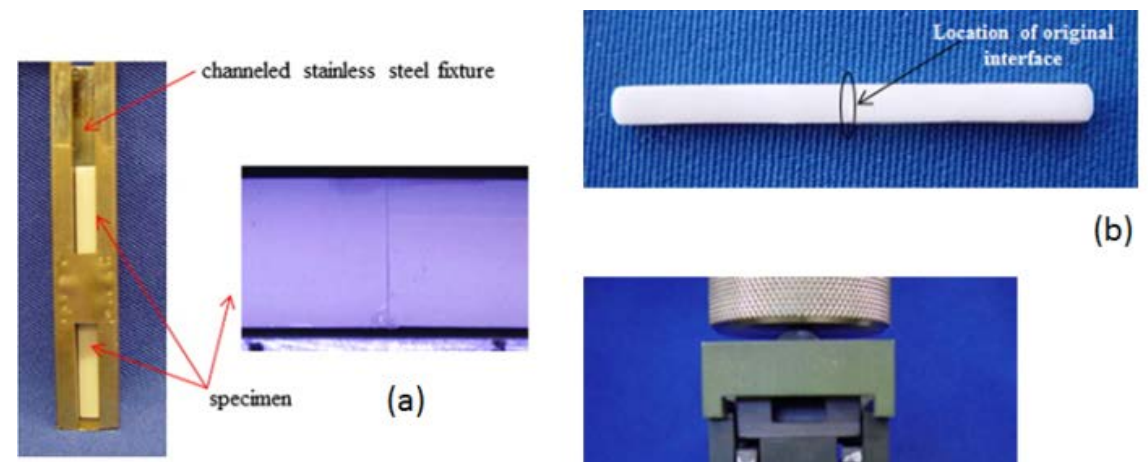

(b)

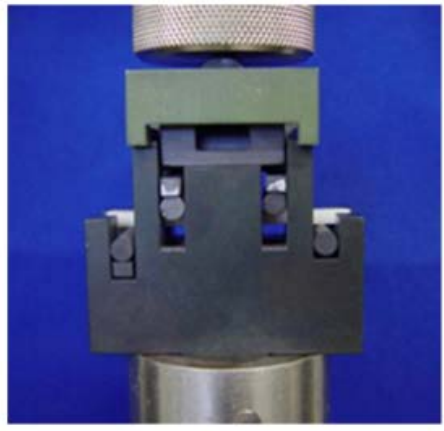

(c)

Figure A4. (a) controlled healing test fixture (b) post-healing glass bar (c) four-point bending test fixture 


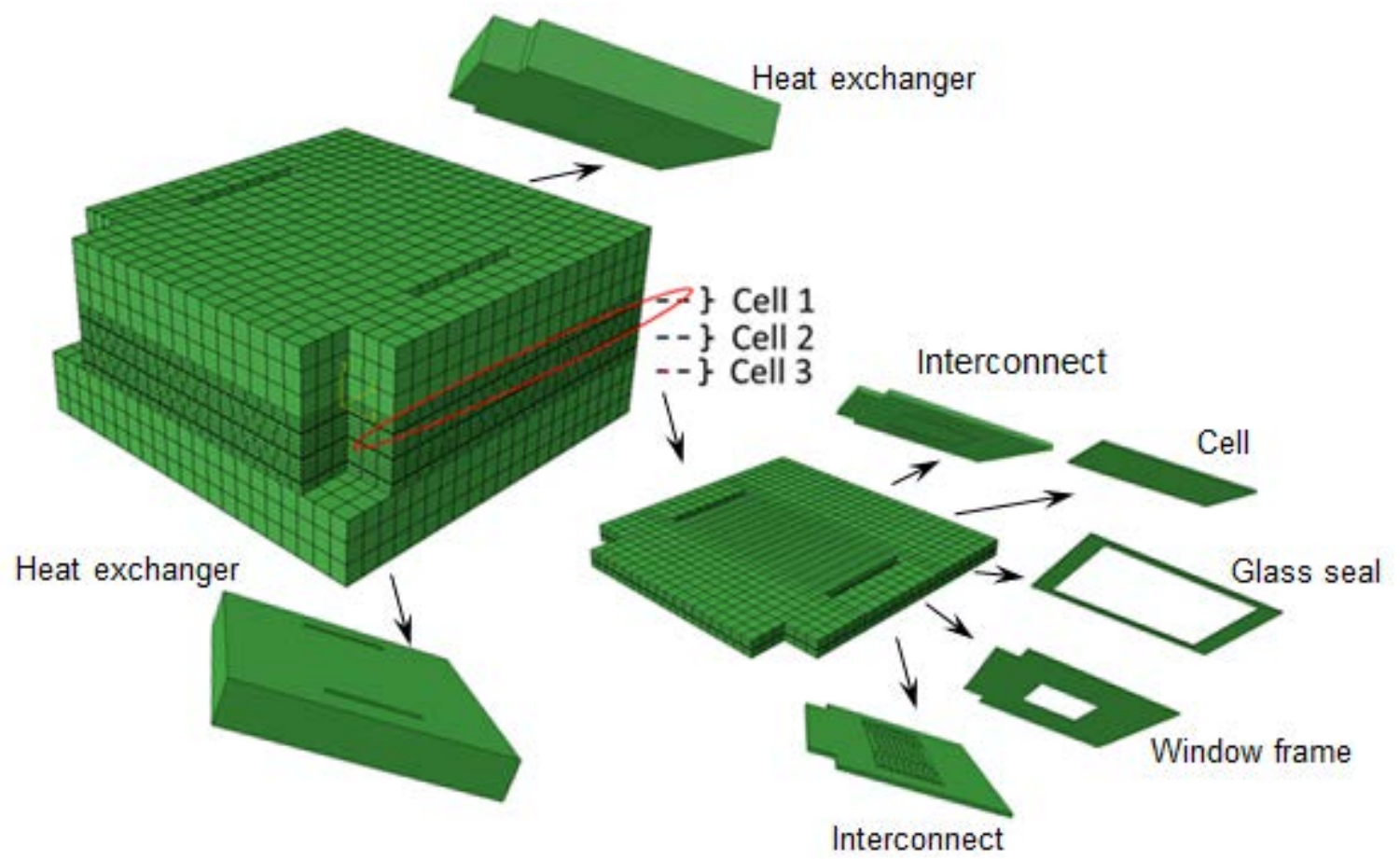

Figure A5. Finite element model of multi-cell SOFC stacks
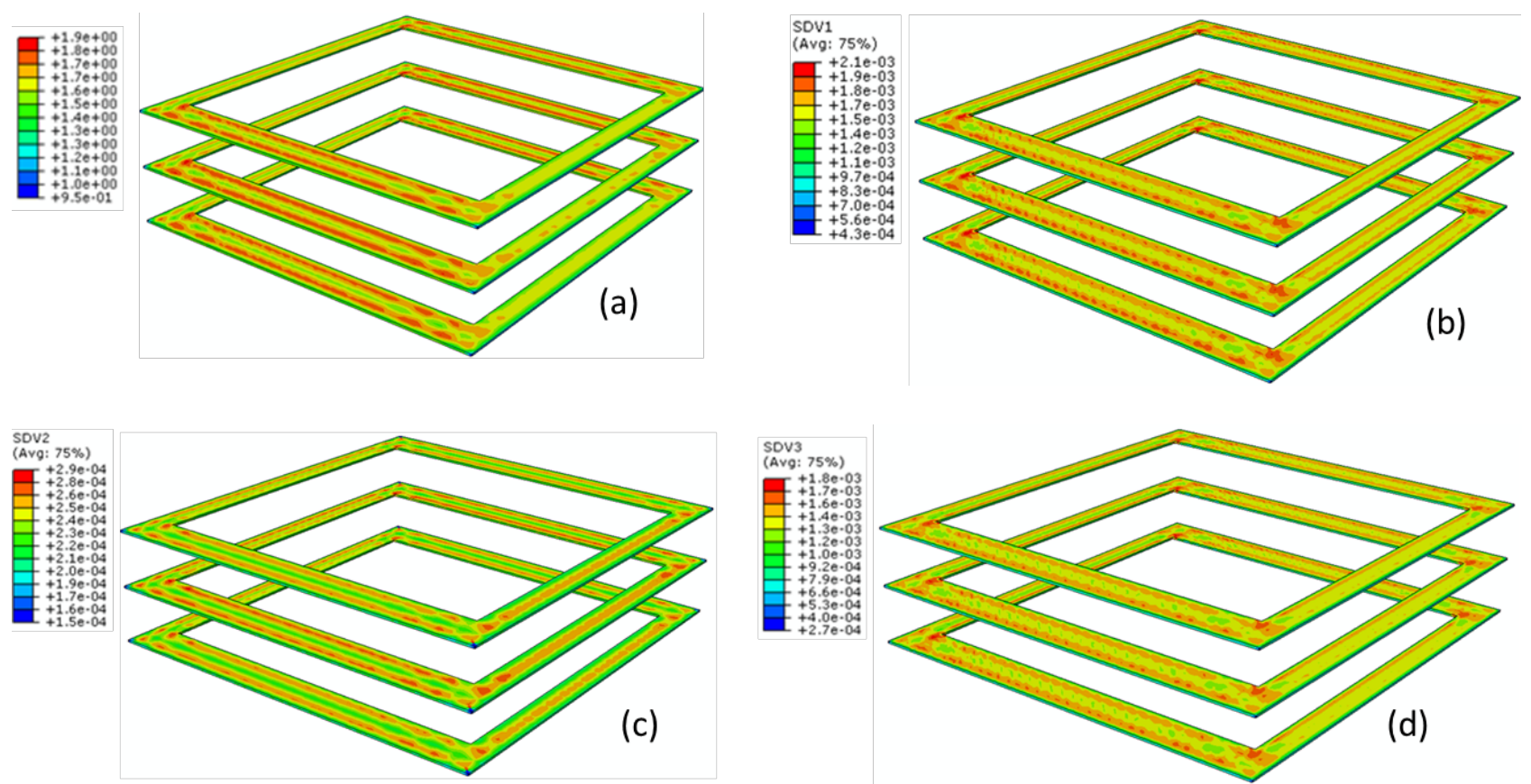

Figure A6. Seal performance under thermal loading predictions (a) stress distribution (b) total damage distribution (c) porosity distribution (d) crack distribution 


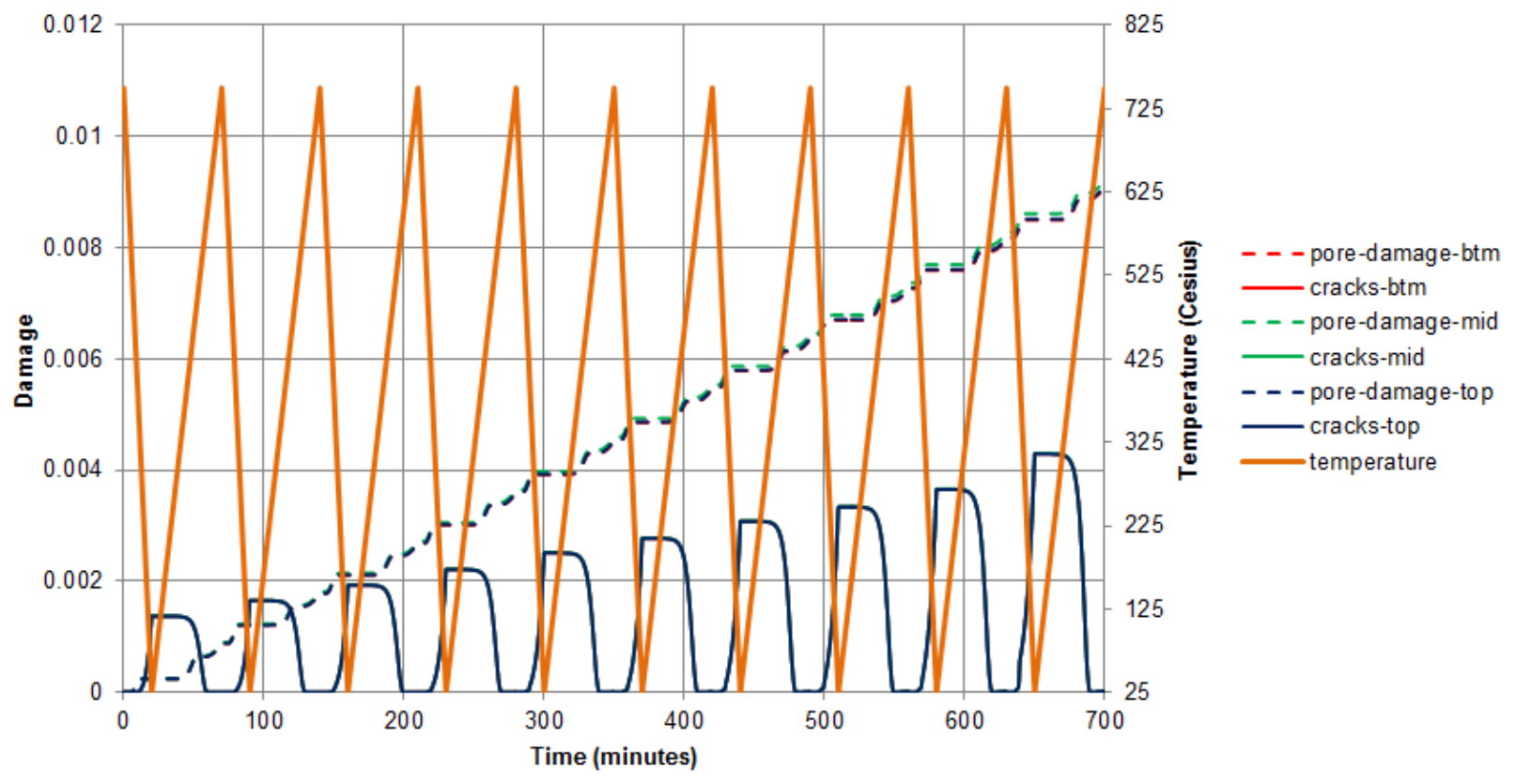

Figure A7. Average damage evolution of the three cell-frame SCN-1 glass seals
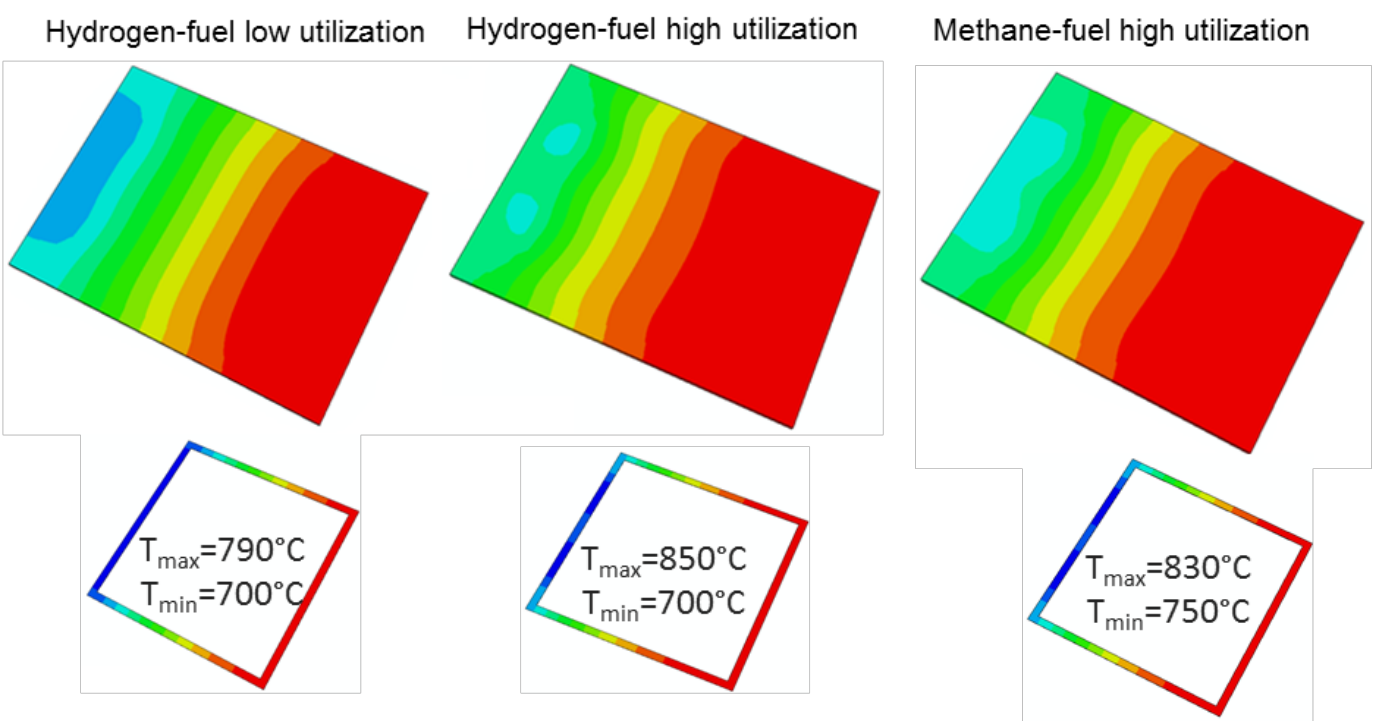

Figure A8. Temperature contours of the SOFC stacks operated with different fuel utilization and compositions 

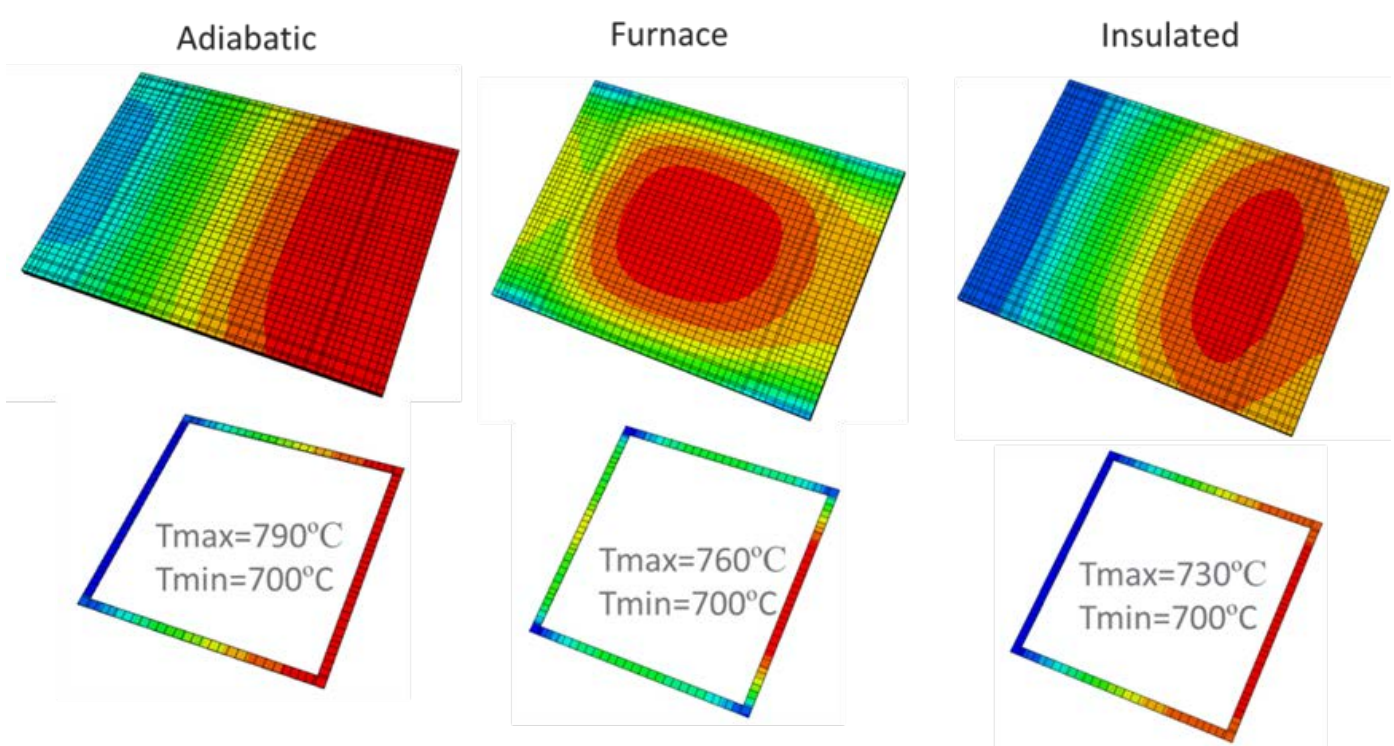

Figure A9. Temperature contours of the SOFC stack under different thermal boundary conditions
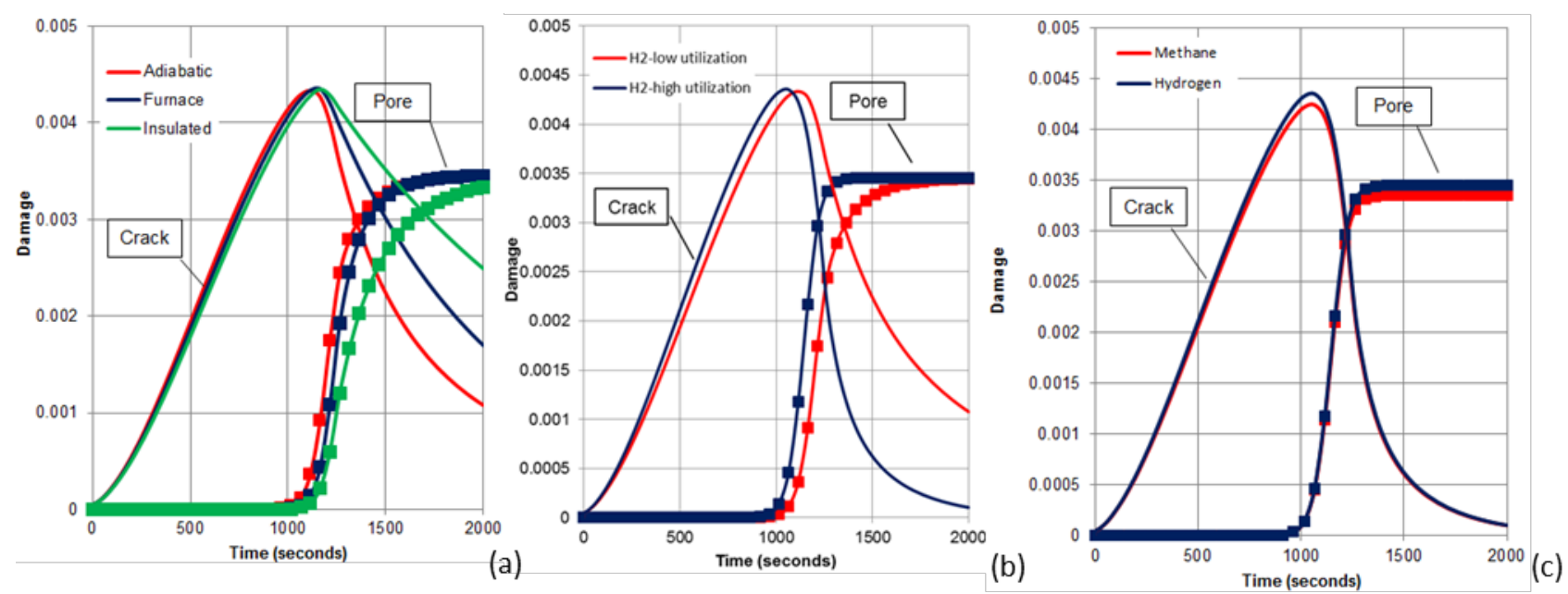

Figure A10. Effects of electrochemical operation parameters (a) thermal boundary conditions (b) fuel utilization (c) fuel composition

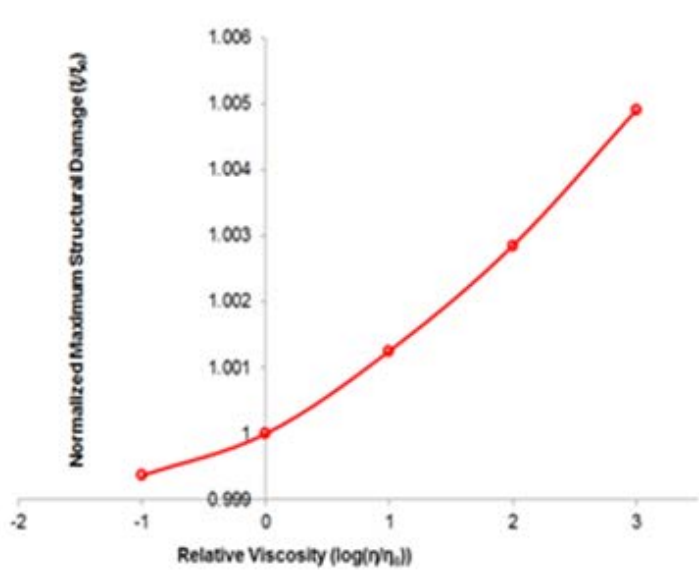

(a)

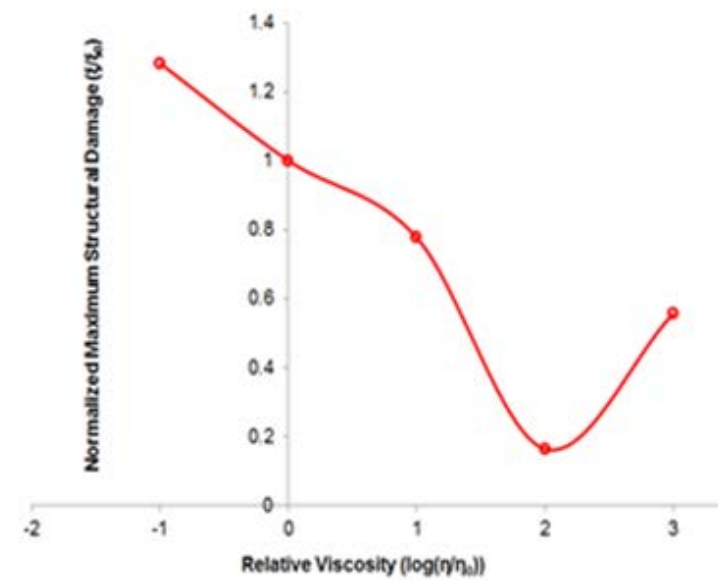

Figure A11. Effects of glass viscosity when (a) cracking (b) pore evolution is dominant 

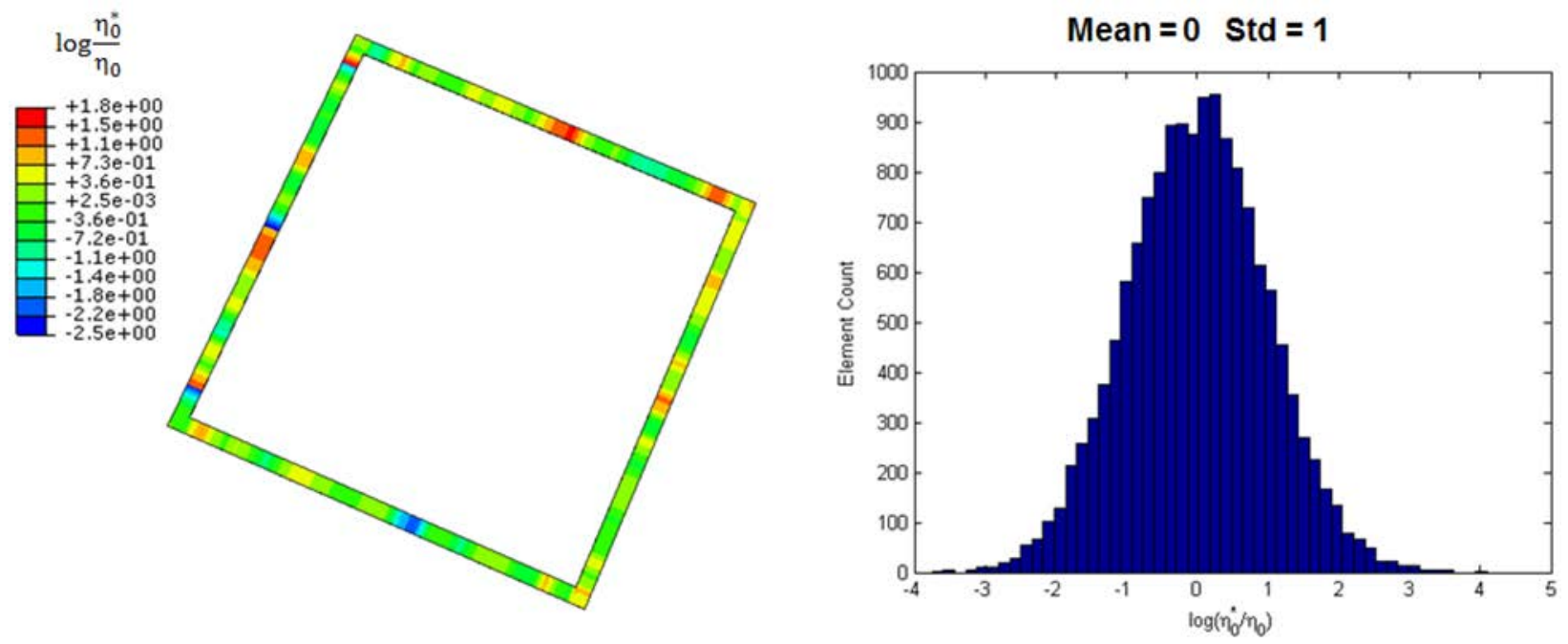

Figure A12. Compliant glass sealant with a heterogeneous viscosity field

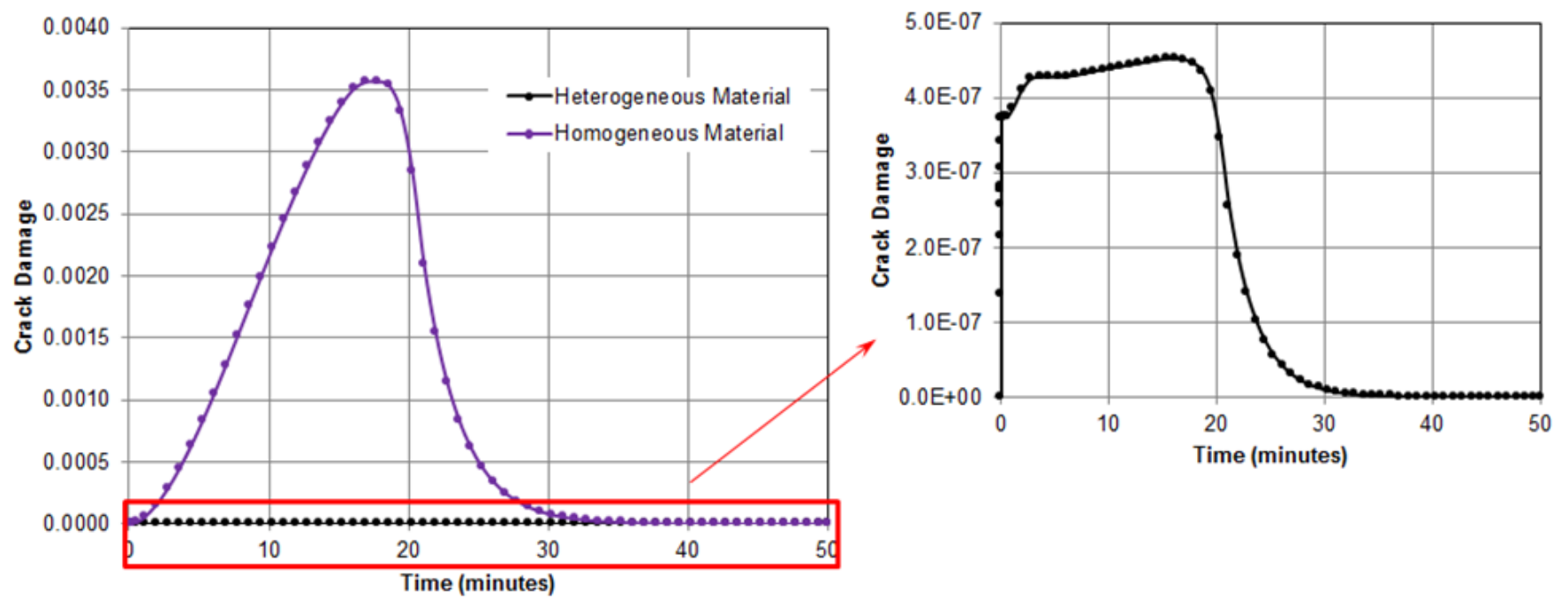

Figure A13. Comparison of crack evolution: heterogeneous glass vs. homogeneous glass 


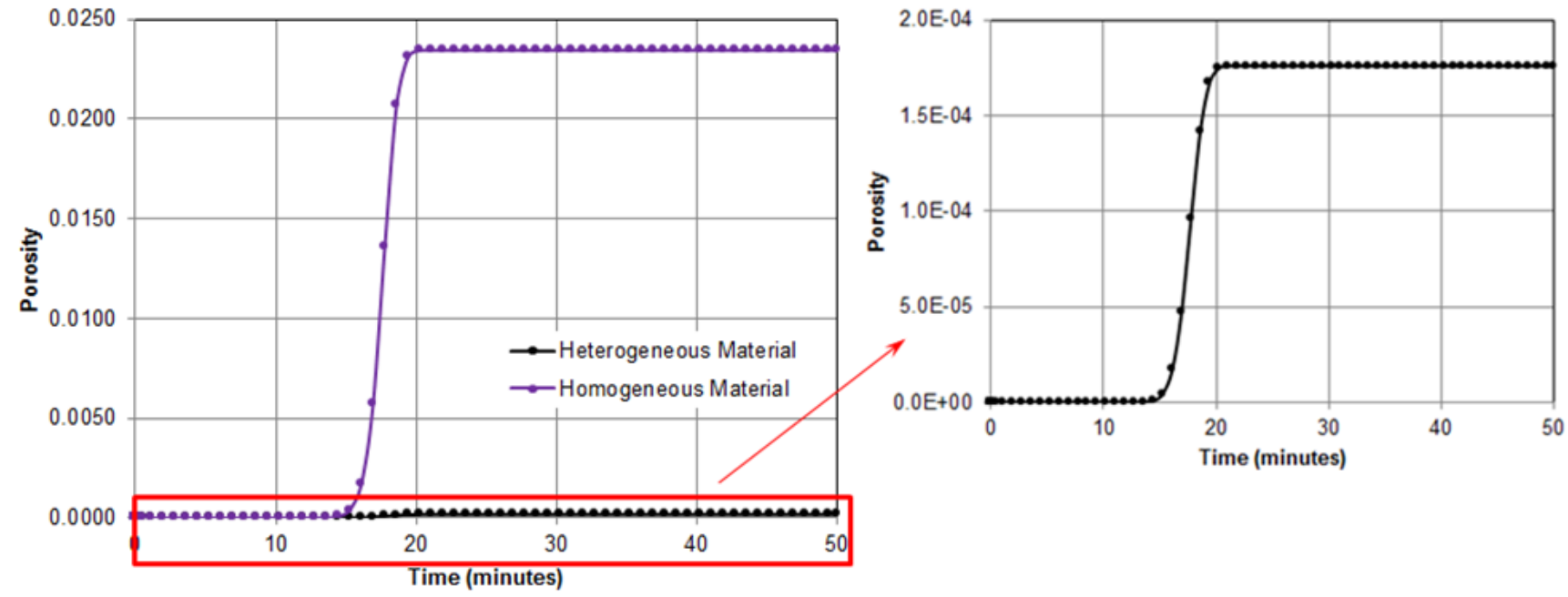

Figure A14. Comparison of pore evolution: heterogeneous glass vs. homogeneous glass
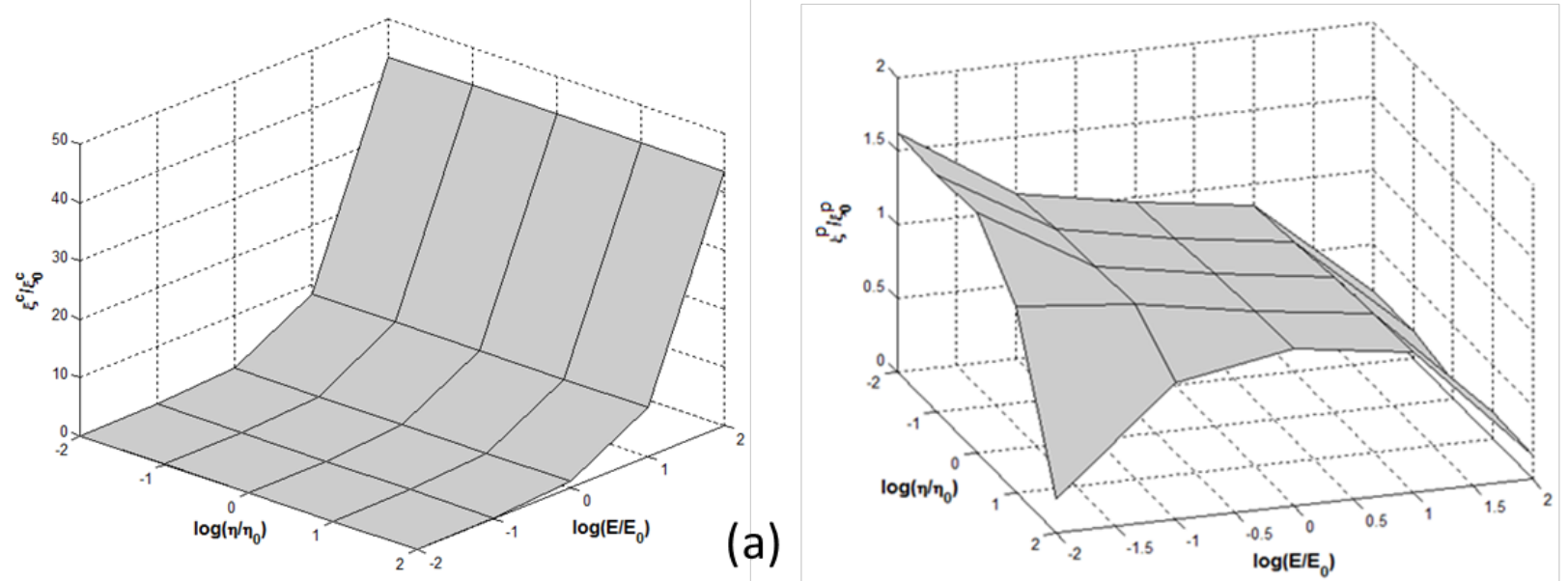

(b)

Figure A15. Mechanical response surface of the compliant glass sealant (a) resistance to cracking damage and $(b)$ resistance to pores 